\title{
Regulation of Tolerance to DNA Alkylating Damage by Dot1 and Rad53 in Saccharomyces cerevisiae
}

Francisco Conde ${ }^{1}$, David Ontoso ${ }^{1}$, Isabel Acosta ${ }^{1}$, Alfonso Gallego-Sánchez ${ }^{2}$, Avelino Bueno $^{2}$ and Pedro A. San-Segundo ${ }^{1, *}$

${ }^{1}$ Instituto de Microbiología Bioquímica and ${ }^{2}$ Instituto de Biología Celular y Molecular del Cáncer. Consejo Superior de Investigaciones Científicas and University of Salamanca, 37007 Salamanca. Spain

\section{* Corresponding author:}

Pedro A. San-Segundo

Instituto de Microbiología Bioquímica. CSIC-USAL

Edificio Departamental. Lab 313-316. Campus Unamuno

37007-Salamanca. Spain

Phone: (34) 923124517. Fax: (34) 923224876.

E-mail: pedross@usal.es 


\section{Keywords:}

Dot1, histone modification, Rad53, TLS, DNA damage tolerance

\section{Abbreviations:}

IR: Ionizing radiation

MMS: Methylmethane sulfonate

PCNA: Proliferating cell nuclear antigen

TLS: Translesion synthesis

UV: Ultraviolet 


\begin{abstract}
To maintain genomic integrity cells have to respond properly to a variety of exogenous and endogenous factors that produce genome injuries and interfere with DNA replication. DNA integrity checkpoints coordinate this response by slowing cell cycle progression to provide time for the cell to repair the damage, stabilizing replication forks and stimulating DNA repair to restore the original DNA sequence and structure. In addition, there are also mechanisms of damage tolerance, such as translesion synthesis (TLS), which are important for survival after DNA damage. TLS allows replication to continue without removing the damage, but results in a higher frequency of mutagenesis. Here, we investigate the functional contribution of the Dot1 histone methyltransferase and the Rad53 checkpoint kinase to TLS regulation in Saccharomyces cerevisiae. We demonstrate that the Dot1-dependent status of H3K79 methylation modulates the resistance to the alkylating agent MMS, which depends on PCNA ubiquitylation at lysine 164. Strikingkly, either the absence of DOT1, which prevents full activation of Rad53, or the expression of an HA-tagged version of RAD53, which produces low amounts of the kinase, confer increased MMS resistance. However, the $\operatorname{dot} 1 \Delta \operatorname{rad53-HA}$ double mutant is hypersensitive to MMS and shows barely detectable amounts of activated kinase. Furthermore, moderate overexpression of $R A D 53$ partially suppresses the MMS resistance of $\operatorname{dot} 1 \Delta$. In addition, we show that MMS-treated $\operatorname{dot} 1 \Delta$ and rad53-HA cells display increased number of chromosomeassociated Rev1 foci. We propose that threshold levels of Rad53 activity exquisitely modulate the tolerance to alkylating damage at least by controlling the abundance of the key TLS factor Rev1 bound to chromatin.
\end{abstract}




\section{Introduction}

The genome is constantly hit by multiple sources of exogenous and endogenous damage that compromise its integrity. Eukaryotic cells respond to the presence of genome injuries by activating surveillance mechanisms referred to as DNA damage or DNA integrity checkpoints. The inability to properly react to DNA damage results in genome instability, which in mammalian systems is linked to tumor development [1-3].

In Saccharomyces cerevisiae, DNA damage is initially detected by the Mec1/Ddc2 (ATR/ATRIP) and the clamp-like Ddc1-Rad17-Mec3 ('9-1-1') complexes. These checkpoint sensors are independently recruited to the sites of damage and trigger the activation of the Rad53 and Chk1 effector kinases in a process mediated by the $\operatorname{Rad} 9$ and Mrc1 adaptors. In turn, the effector kinases act on the corresponding targets to promote the different cellular responses to cope with the DNA damage, including cell cycle arrest, stabilization of replication forks and activation of DNA repair [4].

Eukaryotic cells are equipped with a broad range of specialized DNA repair pathways to confront and eliminate the great variety of genomic insults of different nature that can arise during different cell cycle stages, but lesions occurring during $\mathrm{S}$ phase that can stall replication forks are particularly threatening [5,6]. Thus, in addition to the repair pathways to remove the lesions, cells possess tolerance mechanisms, such as translesion synthesis (TLS) and template switching, that allow replication to continue despite the presence of DNA damage [7]. These tolerance pathways are critical for survival in the face of DNA damage. TLS is mediated by specialized polymerases that, in contrast to replicative polymerases, are able to insert nucleotides opposite damaged templates, although at the cost of increasing the mutagenesis rate. Therefore, this tolerance pathway must be tightly controlled. In yeast, TLS is performed by the Pol $\eta$ polymerase (encoded by the $R A D 30$ gene), and by the Pol $\zeta$ polymerase composed by 
the Rev3 (catalytic) and Rev7 (regulatory) subunits [8]. In addition, the Rev1 protein also plays a critical role in TLS. Although Rev1 possesses deoxycytidyl transferase activity, its main TLS function is structural and does not rely on the catalytic activity $[9,10]$. In eukaryotes, DNA damage tolerance is exquisitely controlled by ubiquitylation of the DNA sliding clamp PCNA at the lysine 164 [11]. Thus, Rad6/Rad18-dependent monoubiquitylation of PCNA-K164 triggers TLS, whereas polyubiquitylation of PCNA-K164 through Ubc13/Mms2/Rad5 induces the template-switch error-free mode of damage bypass by sister-strand recombination [7,12-14].

Genome injuries do not occur on the naked DNA, but rather in the context of the highly organized chromatin. Indeed, during the recent years significant advances have been made in understanding the contribution of chromatin modifications to several aspects of the DNA damage response, such as detection, signaling and repair of the damage [15-20]. However, little is known about how chromatin structure may impinge on DNA damage tolerance, although a recent report has described a role for the INO80 remodeling complex in DNA damage tolerance through modulation of PCNA ubiquitylation [21]. Methylation of lysine 79 in histone H3 (hereafter H3K79-me) by the Dot1 methyltransferase is one of the various histone modifications involved in the cellular responses to DNA damage. Dot1 orchestrates several aspects of chromosome metabolism both in mitotic and meiotic cells, including transcriptional silencing [2225], activation of the meiotic recombination checkpoint and regulation of recombination partner choice in meiosis [26], repair of double-strand breaks by sister-chromatid recombination in mitotic cells [27], and repair of IR- and UV-induced lesions [28-31]. In addition, Dot1 participates in the DNA damage checkpoint in vegetative yeast cells being required for Rad9-mediated activation of the Rad53 effector kinase, at least during the G1-S cell cycle transitions [32,33]. Moreover, we have recently reported that 
Dot1 negatively regulates the Pol $\zeta /$ Rev1-dependent pathway of tolerance to alkylating DNA damage. Indeed, deletion of DOT1 results in increased Rev3-dependent mutagenesis [34]. Dot1 is conserved form yeast to human; importantly, altered function of human DOT1L is linked to leukemia development [35-39].

Here we investigate in more detail how Dot1 function contributes to the regulation of DNA damage tolerance. We find that Dot1 modulates the response to the alkylating agent MMS through its catalytic activity on H3K79. In fact, progressively reduced levels of $\mathrm{H} 3 \mathrm{~K} 79$ trimethylation result in gradually increased resistance to MMS. In addition, we examine the functional interaction between Dot1 and an HAtagged version of the Rad53 checkpoint kinase that also promotes increased MMS resistance and mutagenesis [40]. Our results indicate that there is a window of opportunity for TLS to act in the face of MMS lesions that is delineated by threshold levels of Rad53 activity. Moreover, we present evidence indicating that the contribution of Dot1 to DNA damage tolerance is exerted via Rad53 and controls the levels of Rev1 protein associated with chromosomes. 


\section{Materials and methods}

\subsection{Strains and plasmids}

Yeast strains and plasmids used in this work are listed in Table 1 and Table 2, respectively. REV1-13myc::HISMX6 and rad53-3HA::TRP1 tagging, as well as dot1::kanMX6 gene deletion, were performed using standard PCR-based approaches [41]. Plasmid pSS30 was used to generate dot1::URA3 [26]. Gene modifications were introduced either by direct transformation or by genetic crosses always in an isogenic background. To generate the strains carrying the $\operatorname{dot} 1-G 401 \mathrm{~A}$ and $\operatorname{dot} 1-G 401 \mathrm{~V}$ alleles at the genomic locus, the pRS306-based plasmids pFF003 and pTW043, kindly provided by Fred van Leeuwen (NKI, Netherlands) were cut with $M l u I$ and targeted to the DOTI promoter in dot1::kanMX6 strains lacking the whole DOT1 coding region. Plasmids pRS315-DOT1 and pFvL54, which contain DOT1 and dot1-G401V respectively, in the pRS315 low-copy vector were also provided by F. van Leeuwen [42]. Strains YP712, YP1175, YP1181 and YP1185 carry the zip1::LYS2 deletion. Zip1 is a meiosis-specific structural component of the yeast synaptonemal complex [43]; therefore, the presence or absence of the ZIPI gene does not have any effect in vegetative haploid yeast. Strains harboring the $h h t 1-K 79 A$ and pol30-K164R alleles were kindly provided by Mary Ann Osley (University of New Mexico) and Takashi Hishida (Osaka University), respectively. Functionality of the REVI-myc tagged gene was confirmed by the lack of MMS sensitivity. The high-copy plasmid pSS145 containing RAD53 was constructed by cloning the 3.6-kb EcoRI fragment from pCB583 (provided by the lab of M. Foiani, IFOM, Italy) into the $2 \mu$ vector pRS426. 


\subsection{MMS sensitivity assays}

Exponentially growing cells were serially diluted in water and $5 \mu$ were spotted onto YPDA plates (YPD supplemented with $50 \mu \mathrm{g} / \mathrm{ml}$ adenine) or YPDA plates containing MMS (Sigma) at various concentrations and incubated at $30^{\circ} \mathrm{C}$. MMS plates were always freshly made. When the strains to be analyzed contained plasmids, cells were grown on selective medium (SC) lacking the corresponding nutrient. Quantification of the MMS resistance was carried out by plating the same number of exponentially growing cells onto YPDA and MMS-containing plates. The MMS resistance was determined by counting the colonies growing on MMS plates relative to the YPDA. Colonies were counted using the colony counting tool of the Quantity One software (Bio-Rad). The quantification was always done at least in triplicate. To calculate the statistical significance of differences in MMS resistance in Figure 6C, a two-tailed unpaired Student $t$-test was performed using the GraphPad Prism version 4.0 software.

\subsection{Western blot analysis}

TCA cell extracts were prepared and analyzed essentially as described [34]. SDS-PAGE gels at $15 \%, 10 \%$ and $7.5 \%$ were used for detection of histone $\mathrm{H} 3$, Dot 1 and $\operatorname{Rad} 53$, respectively. Antibodies that specifically recognize H3K79-me1 (ab2886), H3K79-me2 (ab3594), H3K79-me3 (ab2621) and total histone H3 (ab1791) were from Abcam and were used at 1:1000 dilution for H3K79-me1 and 1:4000 dilution for the rest. The antiRad53 (sc-6749; Santa Cruz Biotechnology) and anti-HA (12CA5; Roche) antibodies were used at 1:2000 dilution. The rabbit polyclonal anti-Dot1 antibody was a kind gift from R. Freire (HUC, Tenerife, Spain) and was used at 1:1000 dilution. HRPconjugated secondary antibodies were from Santa Cruz or GE Healthcare. The ECL or ECL-Plus reagents (GE Healthcare) were used for detection. For quantification of 
H3K79 methylation levels, the chemiluminescence signal was captured with a ChemiDoc XRS (Bio-Rad) apparatus and analyzed with the Quantity One software. Only non-saturated bands in the linear range of detection were considered for quantification.

\subsection{Citology}

Immunofluorescence of nuclear spreads was performed essentially as described [44]. The anti-myc tag antibody (clone 4A6, 05-724; Millipore) was used at 1:500 dilution and the Alexa Fluor 594-conjugated anti-mouse secondary antibody (A11032; Molecular Probes) was used at 1:200 dilution. Images were captured using a Nikon Eclipse 90i fluorescence microscope equipped with an Orca-AG (Hamamatsu) CCD camera and a PlanApo VC 100X/1.4 objective. Images were processed and analyzed with the MetaMorph software (Molecular Devices). Quantification of chromosomeassociated Rev1 was performed by counting the number of Rev1 foci in the DAPIstained area delimited using the MetaMorph tools. 


\section{Results}

\subsection{Dot1-dependent histone H3K79 methylation regulates tolerance to alkylating DNA damage}

We have previously reported that the absence of Dot1 results in increased resistance to chronic MMS exposure as a consequence of enhanced TLS-mediated tolerance [34]. The only known biochemical function of Dot1 is the mono-, di-, and trimethylation of lysine 79 in histone H3 [25]. To determine whether regulation of MMS resistance by Dot1 relies on its methyltransferase activity, we analyzed a catalytically-inactive $\operatorname{dot} 1-G 401 \mathrm{~V}$ mutant, in which the glycine at position 401 in the Dot1 active site has been substituted by a valine (Fig. 1A; [45]). Like $\operatorname{dot} 1 \Delta$, the $\operatorname{dot} 1$ G401V mutant completely lacked detectable H3K79 methyltransferase activity (Fig. 1B) and also displayed enhanced MMS resistance relative to the isogenic wild-type strain (Figs. 1C and 2B), indicating that the catalytic activity of Dot1 is required for its function in MMS tolerance. The only known substrate of Dot1 is H3K79; therefore, to confirm that the MMS resistance of $\operatorname{dot} 1 \Delta$ is due to the lack of $\mathrm{H} 3 \mathrm{~K} 79$ methylation, we analyzed an $H 3-K 79 A$ mutant, in which the lysine 79 targeted by Dot1 has been replaced by an alanine and cannot be methylated [46]. Like $\operatorname{dot} 1 \Delta$, the $H 3-K 79 A$ allele conferred increased MMS resistance (Fig. 1D).

To investigate in more detail the regulation of DNA damage tolerance by H3K79 methylation, we examined MMS resistance in strains exhibiting gradually diminished Dot 1 catalytic activity. We utilized the combination of two genetic tools to alter the levels of Dot1 activity: a) use of a $\operatorname{dot1-G401A}$ mutant (Fig. 1A), which produces a partially active protein [42], and b) expression of the gene under its own promoter, but from a single-copy plasmid ( $\mathrm{p}[$ DOT1] or $\mathrm{p}[$ dot 1-G401A]), which results 
in reduced amount of protein (Fig. 2A). Given the distributive mode of action of Dot1 [42], the wild-type strain expressing DOT1 from its endogenous locus displayed the maximal activity with the highest levels of H3K79-me3 and the lowest levels of H3K79-me1 (Fig. 2A). The catalytic activity was then gradually reduced, as manifested by decreasing levels of H3K79-me3 and increasing levels of H3K79-me1, following this sequence: $D O T 1>\mathrm{p}[D O T 1]>\operatorname{dot} 1-G 401 A>\mathrm{p}[\operatorname{dot} 1-G 401 A]>\operatorname{dot} 1-G 401 \mathrm{~V} \approx$ $\operatorname{dot} 1 \Delta$ (Fig: 2A). Interestingly, we found that the progressive reduction of Dot1 activity led to a gradually elevated MMS resistance (Fig. 2B and 2D). In particular, quantification of the relative levels of each methylation state revealed a clear correlation between the drop of H3K79-me3 and the enhanced resistance to MMS (Fig. 2C and 2D). Thus, tolerance to alkylating damage is finely modulated by H3K79 methylation levels.

\subsection{The MMS resistance of $\operatorname{dot} 1 \Delta$ depends on PCNA ubiquitylation at lysine 164}

Our previous observations indicated that the increased MMS resistance and mutagenesis frequency of $\operatorname{dot} 1 \Delta$ is as a consequence of enhanced tolerance mediated by the TLS pathway of DNA damage bypass, because it is abolished in the absence of Pol $/$ Rev1 [34]. DNA damage-induced PCNA ubiquitylation at lysine 164 is carried out by the $\operatorname{Rad} 6 / \operatorname{Rad} 18(\mathrm{E} 2-\mathrm{E} 3)$ complex $[7,11,47]$ and it is a key regulator of the tolerance to genotoxic insults (Fig. 3A; [12]). Therefore, to determine whether the MMS resistance conferred by the absence of Dot1-promoted H3K79 methylation relies on this PCNA modification, we deleted DOT1 in a PCNA ubiquitylation-deficient pol30K164R mutant [48]. As expected, the pol30-K164R mutant was extremely sensitive even to low MMS concentrations (Fig. 3B), underscoring the importance of DNA damage tolerance pathways in promoting viability after alkylating damage [11]. 
However, although the absence of Dot1 suppresses the sensitivity of an ample range of mutants impaired in coping with MMS-induced lesions [34], deletion of DOT1 failed to suppress the MMS sensitivity of pol30-K164R (Fig. 3B). Moreover, the dot1 1 pol30K164R double mutant was more sensitive to MMS than pol30-K164R (Fig. 3B). Likewise, the $\operatorname{rev} 3 \Delta \operatorname{dot} 1 \Delta$ or $\operatorname{rev} 1 \Delta \operatorname{dot} 1 \Delta$ double mutants are also more sensitive to MMS than rev3 $\Delta$ or rev1 $\Delta$ [34]. These observations unveil the additional role of Dot 1 in another process, such as homologous recombination [27], which becomes more relevant to deal with MMS damage in the absence of TLS.

\subsection{Threshold levels of Rad53 activity modulate DNA damage tolerance}

Previous studies have shown that, like $\operatorname{dot} 1 \Delta$, cells expressing an HA-tagged version of the Rad53 checkpoint kinase display increased MMS resistance and increased MMS-induced mutagenesis frequency ([40]; see also Fig. 5C). Moreover, recent observations indicate that the enhanced MMS resistance of rad53-HA also requires PCNA-K164 ubiquitylation (Fig. 3B) and TLS activity (AGS et al., submitted).

Thus, the similar phenotypes of $\operatorname{dot} 1 \Delta$ and $\mathrm{rad} 53-H A$ prompted us to further explore the possible relationship between Dot1 and Rad53 in the regulation of MMS resistance, as we have previously proposed [34]. Indeed, we found that the enhanced MMS resistance of $\operatorname{dot} 1 \Delta$ was abolished in the absence of Rad53 because a rad53 $\Delta$ $\operatorname{dot} 1 \Delta$ double mutant showed similar MMS sensitivity than rad53 $\Delta$ (Fig. 4); therefore, MMS resistance conferred by dot1 $\Delta$ requires Rad53 function.

Activation of Rad53 can be monitored by a well-characterized phosphorylationdependent electrophoretic mobility shift [49]. In the dot1 $\Delta$ mutant, Rad53 is not fully activated in response to MMS ([32]; Fig. 5A, lanes 3 and 4). In contrast, in the rad53$H A$ mutant, although the Rad53-HA protein can be activated to the same extent as the 
wild-type protein, it is produced in much lower amounts and, consequently, also renders reduced levels of Rad53 activity ([40]; Figs. 5A and 5B). These observations suggest that the sub-optimal levels of Rad53 activity present in $\operatorname{dot} 1 \Delta$ or rad53-HA cells lead to increased MMS resistance. Therefore, we generated a dot1 $\Delta$ rad53-HA double mutant to analyze the extent of Rad53-HA phosphorylation (activation) and MMS resistance. Using anti-Rad53 antibodies, the Rad53-HA protein was not detectable in rad53-HA and dotl $\Delta$ rad53-HA cells in the absence of DNA damage (Fig. 5A, lanes 5 and 6). Interestingly, in the dot1 $\Delta$ rad53-HA double mutant, in addition to the low amount of Rad53-HA protein characteristic of this tagged version, the levels of MMS-induced phosphorylated (and therefore active) Rad53-HA were further reduced compared with the rad53-HA single mutant (Fig. 5A, lanes 7 and 8). Indeed, the phosphorylated species of Rad53-HA induced by MMS were only barely detectable after long exposure of the membranes (Fig. 5A, middle panels). Using anti-HA antibodies, it was possible to detect a faint band corresponding to the basal form of Rad53-HA (Fig. 5B, lanes 1 and 2), which was not detectable with anti-Rad53. In addition, upon MMS treatment, only the phosphorylated species of Rad53-HA were detected, and the reduced levels of activated Rad53-HA in the dot1 $\Delta$ rad53-HA double mutant compared with the rad53$H A$ single mutant were also manifested (Fig. 5B, lanes 3-6). Strinkingly, whereas both dot1 $\Delta$ and rad53-HA single mutants display increased MMS resistance (Fig. 5C; see also Figs. 1, 2, 3 and 6; $[34,40])$, the $\operatorname{dot} 1 \Delta$ rad53-HA double mutant was extremely sensitive to MMS (Fig. 5C), resembling a rad53 $\Delta$ mutant (Fig. 4).

Moreover, if the increase in MMS resistance observed in $\operatorname{dot} 1 \Delta$ results from the inability to fully activate Rad53, we reasoned that raising the levels of active Rad53 kinase in the dot1 $\Delta$ mutant by overproducing the protein should bring the MMS resistance closer to wild-type levels. Indeed, we found that moderate overexpression of 
RAD53 from a high-copy plasmid significantly restored the levels of MMS-activated Rad53 in a $\operatorname{dot} 1 \Delta$ mutant (Fig. 6A) and partially suppressed the increased MMS resistance of $\operatorname{dot} 1 \Delta$ (Figs. 6B and 6C). Collectively, these results suggest that intermediate Rad53 activity (below wild-type levels) supports enhanced resistance to MMS, as occurs in dot1 1 or rad53-HA mutants. However, when Rad53 function drops below certain threshold level the cells become very sensitive to this genotoxic agent, which is the situation present in the dot1 $\Delta$ rad53-HA double mutant and in rad53 $\Delta$ (see Discussion).

\subsection{Dot1 and Rad53 modulate binding of Rev1 to Chromatin}

Current models for TLS propose that when the replication machinery stalls at a lesion, binding of the Rev1 protein to monoubiquitylated PCNA serves as scaffold for recruiting the Pol $\zeta$ polymerase to the stalled fork by virtue of the interaction between Rev1 and the Rev7 accessory subunit of Pol [50-52]. This would promote the switch of the replicative polymerase by the TLS polymerase to continue replication past the lesion [53-55]. However, compelling evidence supports that DNA damage tolerance mechanisms function during the $\mathrm{G} 2 / \mathrm{M}$ phase acting on gaps behind replication forks [56-59]. In any case, Rev1 is a key regulator of Pol $\zeta$ activity [10], and it has been shown that forms chromosomal foci $[60,61]$; therefore, we examined MMS-induced Rev1 localization in nuclear spreads of wild-type, dot1 $\Delta$ and $\operatorname{rad53-HA}$ strains.

Chromatin-associated Rev1 signal was observed both in untreated and MMStreated cells (Fig. 7A). To analyze in more detail the binding of Rev1 to chromosomes, we quantified the number of Rev1 foci detected in the nuclear spreads and established three categories (Fig. 7B). In the absence of damage, all strains analyzed contained a high number of Rev1 foci on chromosomes; most nuclei corresponded to class III (i.e., 
more than 30 foci per nucleus). However, after MMS treatment, the number of Rev1 foci remarkably diminished in chromosome spreads from the wild-type strain, but remained high in the $\operatorname{dot} 1 \Delta$ and $\operatorname{rad53}-H A$ mutants (Fig. 7). Indeed, whereas most nuclei from the MMS-treated $\operatorname{dot} 1 \Delta$ and $\operatorname{rad53}-H A$ mutants contained more than 30 Rev1 foci ( $79 \%$ and $61 \%$ of nuclei belonged to class III, respectively), only $34 \%$ of wild-type nuclei fell into this category (Fig. 7B). Representative images of the most abundant class of nuclei for each condition are shown in Fig. 7A.

In summary, these results suggest that full activation of Rad53 promotes Rev1 disassembly from chromosomes upon MMS treatment, but the reduced Rad53 activity present in $\operatorname{dot} 1 \Delta$ and $\mathrm{rad53-HA}$ allows extended Rev1 binding to chromatin accounting for the increased MMS resistance of these mutants. 


\section{Discussion}

We have previously described a role for the histone H3K79 methyltransferase Dot1 in the tolerance to alkylating DNA damage [34]. Here, we have further characterized this function of Dot1 by first analyzing the impact of different methylation states of H3K79 in the response to continuous MMS exposure. We provide evidence indicating that the regulation of DNA damage tolerance by Dot1 depends on its catalytic activity on $\mathrm{H} 3 \mathrm{~K} 79$ and not on other possible unknown substrate(s) because, like $\operatorname{dot} 1 \Delta$, both a catalytically-defective $\operatorname{dot} 1-G 401 \mathrm{~V}$ allele, and a non-methylatable H3-K79A version of histone H3 confer MMS hyper-resistance. To investigate how different degrees of H3K79 methylation affect MMS resistance, we have engineered and analyzed a set of strains with progressively crippled Dot1 activity, ranging between wild-type DOTI and $\operatorname{dot} 1 \Delta$ as the maximal and minimal Dot1 catalytic activity, respectively. We find a striking correlation between the decline of Dot1 activity and the increase in MMS resistance. This correlation was particularly evident for the loss of H3K79-me3, suggesting that this methylation state is the most relevant for the MMS response. Similarly, different functional relevance for the different methylation states of H3K79 in the coordination of DNA repair and checkpoint activation in response to UV has been proposed [62]. In contrast, it has been clearly demonstrated that chromatin silencing relies on global levels of $\mathrm{H} 3 \mathrm{~K} 79$ methylation, and not on specific methylation states [42]. Importantly, the MMS resistance conferred by the absence of Dot1 is independent of the silencing SIR complex [34].

The role of Dot1 in multiple nuclear processes, such as transcriptional silencing, meiotic checkpoint, DNA damage checkpoint or DSB repair, relies on the regulated binding of various key factors to specific chromosomal regions [25-27,33]. In principle, the impact of Dot1 (i.e. H3K79 methylation) in MMS resistance and the higher number 
of MMS-induced chromosome-associated Rev1 foci in the dot $1 \Delta$ mutant could emanate from a direct effect of a peculiar chromatin structure dictated by the H3K79 methylation status modulating the recruitment of the TLS machinery. However, our results support an alternative possibility implying that the effect of Dot1 in DNA damage tolerance is exerted indirectly through the regulation of the Rad53 checkpoint kinase. The fact that a rad53-HA mutant, characterized by reduced levels of the kinase, substantially phenocopies dot $1 \Delta$ in the response to chronic MMS exposure $([34,40]$; this work) suggested a possible relationship between Dot1 and Rad53 in the regulation of tolerance to alkylating damage. Supporting this possibility, we find that the MMS resistance of both $\operatorname{dot} 1 \Delta$ and rad53-HA depends on ubiquitylation of PCNA at K164, which is a crucial regulator of the TLS mechanism of DNA damage tolerance. Moreover, we show here that the increased MMS resistance of the dot1 $\Delta$ mutant depends on Rad53.

Both dot1 $\Delta$ and rad53-HA mutants display enhanced resistance to alkylating damage and increased TLS-dependent MMS-induced mutagenesis. Strinkingly, in both mutants, the levels of Rad53 activated by MMS treatment are reduced compared to the wild type, but for different reasons. In the case of $\operatorname{dot} 1 \Delta, \operatorname{Rad} 53$ is produced at normal levels (see Fig. 5A, lanes 1 and 2 and Fig. 6A, lanes 5 and 7), but the inability to properly recruit the Rad9 adaptor to DNA damage sites results in defective activation of Rad53 ([27,32,33]; Fig. 5). On the other hand, the rad53-HA allele gives rise to a functional protein, which can be fully activated; however, it is highly unstable, resulting in the production of low levels of MMS-induced active kinase ([40]; see also Fig. 5A, lane 7). In the $\operatorname{dot} 1 \Delta \mathrm{rad53}-\mathrm{HA}$ double mutant, the activation of the low amounts of kinase produced by the HA-tagged allele is further hampered by the absence of DOT1 resulting in barely detectable levels of phosphorylated kinase. Remarkably, whereas the dot1 $\Delta$ and rad53-HA single mutants show increased MMS resistance, the dot1 $\Delta$ rad53- 
$H A$ double mutant shows strong MMS sensitivity implying that threshold levels of Rad53 activity determine the outcome of the cellular response to alkylating damage. We favor the scenario presented in Fig. 8 to explain our findings. In the face of MMS challenge that prevents the advance of replication forks, the wild-type strain fully activates $\operatorname{Rad} 53$ and the subsequent checkpoint responses controlled by this effector kinase, including cell cycle arrest, stabilization of replication forks and induction of DNA repair mechanisms [5]. In addition, high levels of $\operatorname{Rad} 53$ activity would negatively regulate the TLS mechanism of damage tolerance to prevent excessive mutagenesis. We propose that the sub-optimal levels of activated Rad53 present in rad53-HA mutants or in mutants that cripple H3K79 methylation (dot1-G401A, dot1$G 401 V$, dot1 1 ), while still preventing replication fork collapse, allow cell cycle progression and TLS-dependent replication across damage. Consistent with this idea, analysis of MMS-treated cells lacking the Rad53 phosphatases Pph3 an Ptc2 suggested that a graded response to the level of $\operatorname{Rad} 53$ phosphorylation occurs controlling replication fork restart $[63,64]$. These authors propose that a cycle of Rad53 activation and deactivation coordinates DNA repair with TLS-dependent replication fork progression through damaged DNA by a mechanism involving the Cdc7-Dbf4 kinase activity [64]. Indeed, the cooperation of a functional Rad53-dependent checkpoint response with multiple pathways involving base excision repair, recombination and DNA damage tolerance has been shown to be crucial for a proper cellular response to alkylated DNA $[65,66]$. Our analysis of the dotl $\Delta$ rad53-HA double mutant suggests that when Rad53 activity drops below a critical threshold level, damaged replication forks would irreversibly collapse, like in rad53 $[67,68]$, resulting in cell death and pronounced MMS sensitivity (Fig. 8). We note, however, that in contrast with rad53 $\Delta$, 
the low amounts of the Rad53-HA protein in the dot1 $\Delta$ rad53-HA mutant must be sufficient to support viability in undamaged cells.

The Rev1 protein is a crucial regulator of TLS activity because of its structural function [10]; therefore, we focused on Rev1 to investigate how Dot1/Rad53 function impinges on TLS-dependent mutagenic bypass of MMS-induced lesions. In particular, we examined Rev1 localization to chromatin by immunofluorescence of nuclear spreads. We found that Rev1 foci are present in most nuclei even in the absence of MMS damage, suggesting that there is a constitutive localization of Rev1 to chromosomes. Similar results have been reported for 4NQO-treated cells [61]. Since PCNA ubiquitylation is triggered by DNA damage [11], these observations imply that the basal formation of Rev1 foci does not depend on the interaction with ubiquitylated PCNA. Consistent with this possibility, we detect Rev1 foci in the ubiquitylationdeficient pol30-K164R mutant (Supplementary Figure 1). In fact, studies of mouse and yeast Rev1 suggest that the BRCT domain of Rev1 is required for its constitutive recruitment to foci, whereas the ubiquitin-binding motifs specifically drive Rev1 to damaged replication forks $[60,69,70]$. Moreover, in DT40 chicken cells, Rev1 maintains progression of replication forks upon DNA damage independently of PCNA ubiquitylation [71].

Strikingly, although most nuclei maintain Rev1 signal, we observe a decrease in the number of Rev1 foci per nucleus in MMS-treated wild-type cells. Since mutagenic TLS is induced by alkylating damage [34], this reduced number of Rev1 foci (or a significant fraction of them) must by actively engaged in TLS. In contrast, the number of chromatin-bound Rev1 foci remains elevated in the dot1 $\Delta$ or rad53-HA mutants, providing the opportunity for more TLS-dependent mutagenic events once DNA damage-induced ubiquitylation of PCNA occurs. We propose that full activation of the 
Rad53 checkpoint kinase, which depends on Dot1, somehow restrains TLS activity by preventing promiscuous formation of Rev1 foci associated with chromosomes. Rev1 undergoes Mec1-dependent phosphorylation, which promotes Pol $\zeta$ activity only in NER-deficient cells $[61,72]$. Phosphorylation of Rev1 also requires the checkpoint clamp '9-1-1' and the clamp loader $\operatorname{Rad} 24$; however, it is independent of $\operatorname{Rad} 53$ [72]. Therefore, it is unlikely that this posttranslational modification of Rev1 controls the formation of TLS-active Rev1 foci. Perhaps, Rad53 acts on other regulators of TLS that mediate Rev1 chromosomal binding or stability. Future studies will be aimed to unveil these mechanisms.

In summary, our studies provide insight into how a chromatin modification, namely Dot1-dependent H3K79 methylation, regulates the tolerance to alkylating damage by TLS through modulation of Rad53 activity. TLS constitutes one important aspect of the coordinated global cellular response to DNA damage because of the ability to bypass lesions that impede replication progression, thus preventing fork collapse and eventual formation of DNA breaks potentially leading to chromosomal rearrangements. However, given the error-prone nature of TLS, this process must be kept under strict control to avoid excessive mutagenesis, which can also have deleterious consequences. Therefore, an appropriate balance between error-prone and error-free processes to face DNA damage is essential to avoid genomic instability, which is directly linked to cancer development. Our studies in yeast reveal that the conserved Rad53 checkpoint kinase contributes to finely tune this balance at least by regulating the levels of chromatinbound Rev1. Recent studies using a mouse model point to the influence of correct Rev1 levels in reducing the incidence of carcinogen-induced lung cancer [73], highlighting the importance of these mechanisms for the maintenance of genomic stability. 


\section{Conflict of interest statement}

None

\section{Acknowledgements}

We thank M. Foiani, T. Hishida, R. Rothstein, M.A. Osley and G.C. Walker for providing plasmids and/or strains. We are indebted to F. van Leeuwen for sharing reagents and results prior to publication. We are especially grateful to R. Freire for raising the anti-Dot1 antibody and to F. Prado and J.A. Tercero for comments on the manuscript. DO and AGS were supported by predoctoral fellowships from CSIC and MEC (Spain), respectively. Research in our labs is supported by grants from Ministry of Science and Innovation of Spain (BFU2009-06938 to AB and BFU2009-07159 to PSS) and a grant from Fundación Ramón Areces to PSS. 


\section{REFERENCES}

[1] A. Aguilera and B. Gomez-Gonzalez, Genome instability: a mechanistic view of its causes and consequences, Nat. Rev. Genet. 9 (2008) 204-217.

[2] M.B. Kastan and J. Bartek, Cell-cycle checkpoints and cancer, Nature 432 (2004) 316-323.

[3] C. Kerzendorfer and M. O'Driscoll, Human DNA damage response and repair deficiency syndromes: linking genomic instability and cell cycle checkpoint proficiency, DNA Repair 8 (2009) 1139-1152.

[4] J.C. Harrison and J.E. Haber, Surviving the breakup: the DNA damage checkpoint, Annu. Rev. Genet. 40 (2006) 209-235.

[5] D. Branzei and M. Foiani, Maintaining genome stability at the replication fork, Nat. Rev. Mol. Cell. Biol. 11 (2010) 208-219.

[6] A.M. Friedel, B.L. Pike and S.M. Gasser, ATR/Mec1: coordinating fork stability and repair, Curr. Opin. Cell Biol. 21 (2009) 237-244.

[7] H.D. Ulrich, The RAD6 pathway: control of DNA damage bypass and mutagenesis by ubiquitin and SUMO, Chembiochem 6 (2005) 1735-1743.

[8] B.A. Kunz, A.F. Straffon and E.J. Vonarx, DNA damage-induced mutation: tolerance via translesion synthesis, Mutat. Res. 451 (2000) 169-185.

[9] P.L. Andersen, F. Xu and W. Xiao, Eukaryotic DNA damage tolerance and translesion synthesis through covalent modifications of PCNA, Cell. Res. 18 (2008) 162-173. 
[10] L.S. Waters, B.K. Minesinger, M.E. Wiltrout, S. D'Souza, R.V. Woodruff and G.C. Walker, Eukaryotic translesion polymerases and their roles and regulation in DNA damage tolerance, Microbiol. Mol. Biol. Rev. 73 (2009) 134-154.

[11] C. Hoege, B. Pfander, G.L. Moldovan, G. Pyrowolakis and S. Jentsch, RAD6dependent DNA repair is linked to modification of PCNA by ubiquitin and SUMO, Nature 419 (2002) 135-141.

[12] A. Gallego-Sanchez, F. Conde, P. San Segundo and A. Bueno, Control of PCNA deubiquitylation in yeast, Biochem. Soc. Trans. 38 (2010) 104-109.

[13] H.L. Klein, Reversal of fortune: Rad5 to the rescue, Mol. Cell 28 (2007) 181183.

[14] S. Prakash, R.E. Johnson and L. Prakash, Eukaryotic translesion synthesis DNA polymerases: specificity of structure and function, Annu. Rev. Biochem. 74 (2005) 317-353.

[15] Y. Bao and X. Shen, Chromatin remodeling in DNA double-strand break repair, Curr. Opin. Genet. Dev. 17 (2007) 126-131.

[16] M. Downey and D. Durocher, $\gamma \mathrm{H} 2 \mathrm{AX}$ as a checkpoint maintenance signal, Cell Cycle 5 (2006) 1376-1381.

[17] J.A. Downs, M.C. Nussenzweig and A. Nussenzweig, Chromatin dynamics and the preservation of genetic information, Nature 447 (2007) 951-958.

[18] C.L. Peterson and J. Cote, Cellular machineries for chromosomal DNA repair, Genes Dev. 18 (2004) 602-616. 
[19] T. Schleker, S. Nagai and S.M. Gasser, Posttranslational modifications of repair factors and histones in the cellular response to stalled replication forks, DNA Repair 8 (2009) 1089-1100.

[20] H. van Attikum and S.M. Gasser, The histone code at DNA breaks: a guide to repair?, Nat. Rev. Mol. Cell. Biol. 6 (2005) 757-765.

[21] K.B. Falbo, C. Alabert, Y. Katou, S. Wu, J. Han, T. Wehr, J. Xiao, X. He, Z. Zhang, Y. Shi, K. Shirahige, P. Pasero and X. Shen, Involvement of a chromatin remodeling complex in damage tolerance during DNA replication, Nat. Struct. Mol. Biol. 16 (2009) 1167-1172.

[22] Q. Feng, H. Wang, H.H. Ng, H. Erdjument-Bromage, P. Tempst, K. Struhl and Y. Zhang, Methylation of H3-lysine 79 is mediated by a new family of HMTases without a SET domain, Curr. Biol. 12 (2002) 1052-1058.

[23] N. Lacoste, R.T. Utley, J.M. Hunter, G.G. Poirier and J. Cote, Disruptor of telomeric silencing-1 is a chromatin-specific histone H3 methyltransferase, J. Biol. Chem. 277 (2002) 30421-30424.

[24] H.H. Ng, Q. Feng, H. Wang, H. Erdjument-Bromage, P. Tempst, Y. Zhang and K. Struhl, Lysine methylation within the globular domain of histone H3 by Dot1 is important for telomeric silencing and Sir protein association, Genes Dev. 16 (2002) 1518-1527.

[25] F. van Leeuwen, P.R. Gafken and D.E. Gottschling, Dot1p modulates silencing in yeast by methylation of the nucleosome core, Cell 109 (2002) 745-756. 
[26] P.A. San-Segundo and G.S. Roeder, Role for the silencing protein Dot1 in meiotic checkpoint control, Mol. Biol. Cell 11 (2000) 3601-3615.

[27] F. Conde, E. Refolio, V. Cordon-Preciado, F. Cortes-Ledesma, L. Aragon, A. Aguilera and P.A. San-Segundo, The Dot1 histone methyltransferase and the Rad9 checkpoint adaptor contribute to cohesin-dependent double-strand break repair by sister chromatid recombination in Saccharomyces cerevisiae, Genetics $182(2009)$ 437-446.

[28] L.J. Bostelman, A.M. Keller, A.M. Albrecht, A. Arat and J.S. Thompson, Methylation of histone H3 lysine-79 by Dot1p plays multiple roles in the response to UV damage in Saccharomyces cerevisiae, DNA Repair 6 (2007) 383-395.

[29] J.C. Game, M.S. Williamson and C. Baccari, X-ray survival characteristics and genetic analysis for nine Saccharomyces deletion mutants that show altered radiation sensitivity, Genetics 169 (2005) 51-63.

[30] J.C. Game, M.S. Williamson, T. Spicakova and J.M. Brown, The RAD6/BRE1 histone modification pathway in Saccharomyces confers radiation resistance through a $R A D 51$-dependent process that is independent of $R A D 18$, Genetics 173 (2006) 1951-1968.

[31] G.W. Toh, A.M. O'Shaughnessy, S. Jimeno, I.M. Dobbie, M. Grenon, S. Maffini, A. O'Rorke and N.F. Lowndes, Histone H2A phosphorylation and H3 methylation are required for a novel Rad9 DSB repair function following checkpoint activation, DNA Repair 5 (2006) 693-703. 
[32] M. Giannattasio, F. Lazzaro, P. Plevani and M. Muzi-Falconi, The DNA damage checkpoint response requires histone $\mathrm{H} 2 \mathrm{~B}$ ubiquitination by Rad6-Bre1 and $\mathrm{H} 3$ methylation by Dot1, J. Biol. Chem. 280 (2005) 9879-9886.

[33] R. Wysocki, A. Javaheri, S. Allard, F. Sha, J. Cote and S.J. Kron, Role of Dot1dependent histone H3 methylation in G1 and S phase DNA damage checkpoint functions of Rad9, Mol. Cell. Biol. 25 (2005) 8430-8443.

[34] F. Conde and P.A. San-Segundo, Role of Dot1 in the Response to Alkylating DNA Damage in Saccharomyces cerevisiae: Regulation of DNA Damage Tolerance by the Error-Prone Polymerases Pol $/$ Rev1, Genetics 179 (2008) 1197-1210.

[35] M.G. Guenther, L.N. Lawton, T. Rozovskaia, G.M. Frampton, S.S. Levine, T.L. Volkert, C.M. Croce, T. Nakamura, E. Canaani and R.A. Young, Aberrant chromatin at genes encoding stem cell regulators in human mixed-lineage leukemia, Genes Dev. 22 (2008) 3403-3408.

[36] A.V. Krivtsov, Z. Feng, M.E. Lemieux, J. Faber, S. Vempati, A.U. Sinha, X. Xia, J. Jesneck, A.P. Bracken, L.B. Silverman, J.L. Kutok, A.L. Kung and S.A. Armstrong, H3K79 methylation profiles define murine and human MLL-AF4 leukemias, Cancer Cell 14 (2008) 355-368.

[37] Y.H. Lin, P.M. Kakadia, Y. Chen, Y.Q. Li, A.J. Deshpande, C. Buske, K.L. Zhang, Y. Zhang, G.L. Xu and S.K. Bohlander, Global reduction of the epigenetic H3K79 methylation mark and increased chromosomal instability in CALM-AF10-positive leukemias, Blood 114 (2009) 651-658. 
[38] Y. Okada, Q. Feng, Y. Lin, Q. Jiang, Y. Li, V.M. Coffield, L. Su, G. Xu and Y. Zhang, hDOT1L links histone methylation to leukemogenesis, Cell 121 (2005) 167-178.

[39] Y. Okada, Q. Jiang, M. Lemieux, L. Jeannotte, L. Su and Y. Zhang, Leukaemic transformation by CALM-AF10 involves upregulation of Hoxa5 by hDOT1L, Nat. Cell. Biol. 8 (2006) 1017-1024.

[40] V. Cordon-Preciado, S. Ufano and A. Bueno, Limiting amounts of budding yeast Rad53 S-phase checkpoint activity results in increased resistance to DNA alkylation damage, Nucleic Acids Res. 34 (2006) 5852-5862.

[41] M.S. Longtine, A. McKenzie, 3rd, D.J. Demarini, N.G. Shah, A. Wach, A. Brachat, P. Philippsen and J.R. Pringle, Additional modules for versatile and economical PCR-based gene deletion and modification in Saccharomyces cerevisiae, Yeast 14 (1998) 953-961.

[42] F. Frederiks, M. Tzouros, G. Oudgenoeg, T. van Welsem, M. Fornerod, J. Krijgsveld and F. van Leeuwen, Nonprocessive methylation by Dot1 leads to functional redundancy of histone H3K79 methylation states, Nat. Struct. Mol. Biol. 15 (2008) 550-557.

[43] M. Sym, J.A. Engebrecht and G.S. Roeder, ZIP1 is a synaptonemal complex protein required for meiotic chromosome synapsis, Cell 72 (1993) 365-378.

[44] P.A. San-Segundo and G.S. Roeder, Pch2 links chromatin silencing to meiotic checkpoint control, Cell 97 (1999) 313-324. 
[45] K. Sawada, Z. Yang, J.R. Horton, R.E. Collins, X. Zhang and X. Cheng, Structure of the conserved core of the yeast Dot1p, a nucleosomal histone H3 lysine 79 methyltransferase, J. Biol. Chem. 279 (2004) 43296-43306.

[46] A.B. Fleming, C.F. Kao, C. Hillyer, M. Pikaart and M.A. Osley, H2B ubiquitylation plays a role in nucleosome dynamics during transcription elongation, Mol. Cell 31 (2008) 57-66.

[47] S. Bergink and S. Jentsch, Principles of ubiquitin and SUMO modifications in DNA repair, Nature 458 (2009) 461-467.

[48] T. Hishida, T. Ohya, Y. Kubota, Y. Kamada and H. Shinagawa, Functional and physical interaction of yeast Mgs1 with PCNA: impact on RAD6-dependent DNA damage tolerance, Mol. Cell. Biol. 26 (2006) 5509-5517.

[49] A. Pellicioli, C. Lucca, G. Liberi, F. Marini, M. Lopes, P. Plevani, A. Romano, P.P. Di Fiore and M. Foiani, Activation of Rad53 kinase in response to DNA damage and its effect in modulating phosphorylation of the lagging strand DNA polymerase, EMBO J. 18 (1999) 6561-6572.

[50] M. Bienko, C.M. Green, N. Crosetto, F. Rudolf, G. Zapart, B. Coull, P. Kannouche, G. Wider, M. Peter, A.R. Lehmann, K. Hofmann and I. Dikic, Ubiquitin-binding domains in $\mathrm{Y}$-family polymerases regulate translesion synthesis, Science 310 (2005) 1821-1824.

[51] S. D'Souza, L.S. Waters and G.C. Walker, Novel conserved motifs in Rev1 Cterminus are required for mutagenic DNA damage tolerance, DNA Repair 7 (2008) 1455-1470. 
[52] C. Guo, P.L. Fischhaber, M.J. Luk-Paszyc, Y. Masuda, J. Zhou, K. Kamiya, C. Kisker and E.C. Friedberg, Mouse Rev1 protein interacts with multiple DNA polymerases involved in translesion DNA synthesis, EMBO J. 22 (2003) 66216630.

[53] N. Acharya, R.E. Johnson, S. Prakash and L. Prakash, Complex formation with Rev1 enhances the proficiency of Saccharomyces cerevisiae DNA polymerase $\zeta$ for mismatch extension and for extension opposite from DNA lesions, Mol. Cell. Biol. 26 (2006) 9555-9563.

[54] A.R. Lehmann, A. Niimi, T. Ogi, S. Brown, S. Sabbioneda, J.F. Wing, P.L. Kannouche and C.M. Green, Translesion synthesis: Y-family polymerases and the polymerase switch, DNA Repair 6 (2007) 891-899.

[55] Z. Zhuang, R.E. Johnson, L. Haracska, L. Prakash, S. Prakash and S.J. Benkovic, Regulation of polymerase exchange between Pol $\eta$ and Pol $\delta$ by monoubiquitination of PCNA and the movement of DNA polymerase holoenzyme, Proc. Natl. Acad. Sci. U S A 105 (2008) 5361-5366.

[56] Y. Daigaku, A.A. Davies and H.D. Ulrich, Ubiquitin-dependent DNA damage bypass is separable from genome replication, Nature 465 (2010) 951-955.

[57] G.I. Karras and S. Jentsch, The RAD6 DNA damage tolerance pathway operates uncoupled from the replication fork and is functional beyond S phase, Cell 141 (2010) 255-267.

[58] M. Lopes, M. Foiani and J.M. Sogo, Multiple mechanisms control chromosome integrity after replication fork uncoupling and restart at irreparable UV lesions, Mol. Cell 21 (2006) 15-27. 
[59] L.S. Waters and G.C. Walker, The critical mutagenic translesion DNA polymerase Rev1 is highly expressed during $\mathrm{G}(2) / \mathrm{M}$ phase rather than $\mathrm{S}$ phase, Proc. Natl. Acad. Sci. U S A 103 (2006) 8971-8976.

[60] C. Guo, T.S. Tang, M. Bienko, J.L. Parker, A.B. Bielen, E. Sonoda, S. Takeda, H.D. Ulrich, I. Dikic and E.C. Friedberg, Ubiquitin-binding motifs in REV1 protein are required for its role in the tolerance of DNA damage, Mol. Cell. Biol. 26 (2006) 8892-8900.

[61] S. Sabbioneda, I. Bortolomai, M. Giannattasio, P. Plevani and M. Muzi-Falconi, Yeast Rev1 is cell cycle regulated, phosphorylated in response to DNA damage and its binding to chromosomes is dependent upon MEC1, DNA Repair 6 (2007) $121-127$.

[62] M.L. Evans, L.J. Bostelman, A.M. Albrecht, A.M. Keller, N.T. Strande and J.S. Thompson, UV sensitive mutations in histone H3 in Saccharomyces cerevisiae that alter specific K79 methylation states genetically act through distinct DNA repair pathways, Curr. Genet. 53 (2008) 259-274.

[63] B.M. O'Neill, S.J. Szyjka, E.T. Lis, A.O. Bailey, J.R. Yates, 3rd, O.M. Aparicio and F.E. Romesberg, Pph3-Psy2 is a phosphatase complex required for Rad53 dephosphorylation and replication fork restart during recovery from DNA damage, Proc. Natl. Acad. Sci. U S A 104 (2007) 9290-9295.

[64] S.J. Szyjka, J.G. Aparicio, C.J. Viggiani, S. Knott, W. Xu, S. Tavare and O.M. Aparicio, Rad53 regulates replication fork restart after DNA damage in Saccharomyces cerevisiae, Genes Dev. 22 (2008) 1906-1920. 
[65] M. Segurado and J.A. Tercero, The S-phase checkpoint: targeting the replication fork, Biol. Cell 101 (2009) 617-627.

[66] M.V. Vazquez, V. Rojas and J.A. Tercero, Multiple pathways cooperate to facilitate DNA replication fork progression through alkylated DNA, DNA Repair 7 (2008) 1693-1704.

[67] J.A. Tercero and J.F. Diffley, Regulation of DNA replication fork progression through damaged DNA by the Mec1/Rad53 checkpoint, Nature 412 (2001) 553557.

[68] J.A. Tercero, M.P. Longhese and J.F. Diffley, A central role for DNA replication forks in checkpoint activation and response, Mol. Cell 11 (2003) 1323-1336.

[69] M.G. Bomar, S. D'Souza, M. Bienko, I. Dikic, G.C. Walker and P. Zhou, Unconventional ubiquitin recognition by the ubiquitin-binding motif within the Y family DNA polymerases 1 and Rev1, Mol. Cell 37 (2010) 408-417.

[70] C. Guo, E. Sonoda, T.S. Tang, J.L. Parker, A.B. Bielen, S. Takeda, H.D. Ulrich and E.C. Friedberg, REV1 protein interacts with PCNA: significance of the REV1 BRCT domain in vitro and in vivo, Mol. Cell 23 (2006) 265-271.

[71] C.E. Edmunds, L.J. Simpson and J.E. Sale, PCNA ubiquitination and REV1 define temporally distinct mechanisms for controlling translesion synthesis in the avian cell line DT40, Mol. Cell 30 (2008) 519-529. 
[72] V. Pages, S.R. Santa Maria, L. Prakash and S. Prakash, Role of DNA damageinduced replication checkpoint in promoting lesion bypass by translesion synthesis in yeast, Genes Dev. 23 (2009) 1438-1449.

[73] C.A. Dumstorf, S. Mukhopadhyay, E. Krishnan, B. Haribabu and W.G. McGregor, REV1 is implicated in the development of carcinogen-induced lung cancer, Mol. Cancer Res. 7 (2009) 247-254.

[74] F. Frederiks, G.J. Heynen, S.J. van Deventer, H. Janssen and F. van Leeuwen, Two Dot1 isoforms in Saccharomyces cerevisiae as a result of leaky scanning by the ribosome, Nucleic Acids Res. 37 (2009) 7047-7058.

[75] B. Rockmill and G.S. Roeder, Meiosis in asynaptic yeast, Genetics 126 (1990) 563-574.

[76] X. Zhao, E.G. Muller and R. Rothstein, A suppressor of two essential checkpoint genes identifies a novel protein that negatively affects dNTP pools, Mol. Cell 2 (1998) 329-340.

[77] C.B. Brachmann, A. Davies, G.J. Cost, E. Caputo, J. Li, P. Hieter and J.D. Boeke, Designer deletion strains derived from Saccharomyces cerevisiae S288C: a useful set of strains and plasmids for PCR-mediated gene disruption and other applications, Yeast 14 (1998) 115-132.

[78] R.S. Sikorski and P. Hieter, A system of shuttle vectors and yeast host strains designed for efficient manipulation of DNA in Saccharomyces cerevisiae, Genetics 122 (1989) 19-27. 
[79] T.W. Christianson, R.S. Sikorski, M. Dante, J.H. Shero and P. Hieter, Multifunctional yeast high-copy-number shuttle vectors, Gene 110 (1992) 119122. 


\section{FIGURE LEGENDS}

Fig. 1 - The regulation of MMS resistance by Dot1 relies on its H3K79 methyltransferase activity. (A) Schematic representation of the Dot1 protein with the glycine at position 401 in the catalytic domain that has been mutated to valine or alanine in the dot 1 alleles generated, as indicated. (B) Western blot analysis of H3K 79 mono-, di- and tri-methylation in wild type (BY4742), dot1 $\Delta$ (NKI3002) and dot1-G401V (NKI3018) strains. Ponceau S staining is shown as a loading control. (C) Five-fold serial dilutions of exponentially growing cells from the strains used in (B) were spotted onto YPDA and $0.025 \%$ MMS plates and incubated for 72 hours. (D) Five-fold serial dilutions of exponentially growing wild-type (YAF120), H3-K79A (YAF124) and $\operatorname{dot} 1 \Delta(\mathrm{YP} 1332)$ cells were spotted onto YPDA and $0.015 \%$ MMS plates and incubated for the indicated time.

Fig. 2 - The status of H3K79 methylation modulates tolerance to MMS. (A) Western blot analysis of strains producing the different versions of Dot 1 either from the endogenous loci (DOT1, dot1-G401A and dot1-G401V) or from a single-copy plasmid $(\mathrm{p}[D O T 1]$ and $\mathrm{p}[\operatorname{dot} 1-G 401 A])$, as indicated. The $\operatorname{dot} 1 \Delta$ mutant was also included. Note that the two isoforms of Dot1 detected correspond to two alternative translational start sites [74]. Exponentially growing cells on SC-Leu were treated with $0.02 \%$ MMS for 2 hours. Cell extracts were analyzed with anti-Dot1 antibodies and with antibodies that specifically recognize the mono-, di- and tri-methylated forms of H3K79 or the total histone H3, as indicated. Strains are: YP712+pRS315 (DOT1), YP1175+pRS315-DOT1 (p[DOT1]), YP1185+pRS315 (dot1-G401A), YP1175+pFvL54 (p[dot1-G401A]), YP1181+pRS315 (dot1-G401V) and YP1175+pRS315 (dot1A). (B) Five-fold serial 
dilutions of cultures from the same strains analyzed in (A) were spotted onto YPDA and $0.015 \%$ MMS plates incubated for the indicated time. (C) Quantification of the relative levels of H3K79 mono-, di- and tri-methylation from the same strains used in (A). The maximum value of each methylation state resulting from the average of three experiments was considered 100\%. (D) Quantification of the MMS resistance. Colonies were counted after $40 \mathrm{~h}$ of incubation on YPDA and $0.015 \%$ MMS plates. Average and standard deviation from three independent counts are presented.

Fig. 3 - The MMS resistance of $\operatorname{dot} 1 \Delta$ and $\operatorname{rad53-HA}$ depends on PCNA-K164 ubiquitylation (A) Schematic diagram of the PCNA sliding clamp with the relevant MMS-induced ubiquitylation event. (B) Five-fold serial dilutions of exponentially growing cells were spotted onto YPDA and $0.0005 \%$ MMS plates. Note that the strong MMS sensitivity of the pol30-K164R mutant requires the use of a very low MMS concentration, at which $\operatorname{dot} 1 \Delta$ and $\operatorname{rad53}-H A$ single mutants do not show increased resistance. Strains are YP813 (wild type), YP1215 (dot1A), YP814 (rad53-HA), YP1553 (pol30-K164R), YP1217 (dot14 pol30-K164R) and YP1554 (rad53-HA pol30K164R).

Fig. 4 - The MMS resistance conferred by $\operatorname{dot} 1 \Delta$ requires Rad53. Five-fold serial dilutions of exponentially growing cells were spotted onto YPDA, $0.00375 \%$ MMS, $0.005 \%$ MMS and $0.01 \%$ MMS plates incubated for the indicated time. Strains are

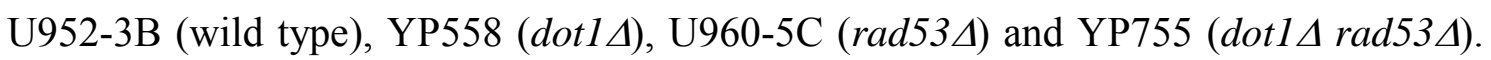
Note that all strains are in an smll background to maintain rad53 $\Delta$ viability. 
Fig. 5 - Analysis of Rad53 activation and MMS resistance in $\operatorname{dot1} \Delta \mathrm{rad53-HA}$. (A) Western blot analysis with anti-Rad53 antibodies of wild-type, $\operatorname{dot} 1 \Delta, \operatorname{rad53}-H A$ and rad53-HA dot $1 \Delta$ exponentially growing cells either untreated or treated with $0.03 \%$ MMS for $1 \mathrm{~h}$, as indicated. Double arrows mark the phosphorylated (activated) species of Rad53 (or Rad53-HA). The middle panels show an overexposure of the film to visualize the low levels of phosphorylated Rad53-HA in the absence of Dot1. Ponceau $\mathrm{S}$ staining was used as a loading control. (B) Western blot analysis with anti-HA antibodies of rad53-HA and rad53-HA dotlA exponentially growing cells either untreated or treated with $0.03 \%$ MMS for $1 \mathrm{~h}$ or $2 \mathrm{~h}$, as indicated. The wild-type strain was included as an untagged control. Double arrows mark the phosphorylated (activated) species of Rad53-HA. The middle panel represents a computer-enhanced display of the upper blot to make more perceptible the basal form of Rad53-HA detected only in untreated cells (single arrow). Ponceau S staining was used as a loading control. (C) Five-fold serial dilutions of exponentially growing cells were spotted onto YPDA, $0.015 \%$ MMS and 0.02\% MMS plates incubated for the indicated time. Strains are YP813 (wild type), YP1215 (dot1 A), YP814 (rad53-HA) and YP1216 (rad53-HA $\operatorname{dot} 1 \Delta)$

Fig. 6 - Overexpression of $R A D 53$ partially suppresses the increased MMS resistance of $\operatorname{dot} \mathbf{1} \Delta$. (A) Western blot analysis of Rad53 in wild-type (YP813) and dot1 $\Delta$ strains (YP1215) transformed with vector alone (pRS426; lanes 5-8) or with a high-copy plasmid expressing RAD53 (pSS145; lanes 1-4) either untreated or treated with $0.03 \%$ MMS for $1.5 \mathrm{~h}$, as indicated. Double arrows mark the phosphorylated species of Rad53. Ponceau S was used as a loading control. (B) 2.5-fold serial dilutions of cells grown on SC-Ura to log phase were spotted onto YPDA and $0.025 \%$ MMS 
plates incubated for the indicated time. Strains are YP813+pRS426 (wild type),

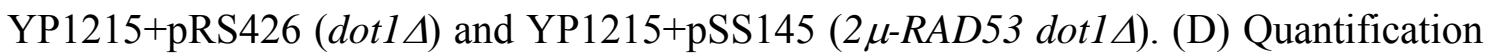
of the MMS resistance. Colonies were counted after $48 \mathrm{~h}$ of incubation on YPDA and $0.025 \%$ MMS plates. Average and standard deviation from six independent counts are presented. The $p$ value of the statistical comparison is also shown.

Fig. 7 - The $\operatorname{dot} 1 \Delta$ and $\operatorname{rad53}-H A$ mutants display increased number of chromosome-associated Rev1 foci upon MMS treatment. (A) Spread nuclei of wildtype (YP1471), dot1 $\Delta$ (YP1458) and rad53-HA (YP1460) strains carrying REV1 tagged with the myc epitope, as well as the untagged control strain (YP813), were stained with DAPI (blue) and anti-myc antibodies (red). Cells were untreated (upper panels) or treated with $0.03 \%$ MMS for $1 \mathrm{~h}$ (lower panels). Representative nuclei of the indicated categories (see below) are presented. (B) Quantification of the number of Rev1 foci in spread nuclei of the strains analyzed in (A) either untreated (left graph) or treated with MMS (right graph). The nuclei were classified in three categories according to the number of chromatin-bound Rev1 foci, as indicated. The percentage of nuclei belonging to each category is represented. The number of nuclei analyzed for each strain is indicated (n).

Fig. 8 - Threshold levels of Rad53 activity modulate the tolerance to alkylating DNA damage. See discussion for details. 
Table 1. Saccharomyces cerevisiae strains

\begin{tabular}{|c|c|c|}
\hline Strain & Genotype & Source/Reference \\
\hline BR1919a & MATa leu2-3,112 his4-260 ura3-1 ade2-1 thr1-4 trp1-289 & [75] \\
\hline YP712 & BR1919a lys2 $\triangle$ NheI zip1::LYS2 & This study \\
\hline YP1175 & BR1919a lys2 $\triangle$ NheI zip1::LYS2 dot1::kanMX6 & This study \\
\hline YP1181 & $\begin{array}{l}\text { BR1919a lys } 24 \text { NheI zip1::LYS2 dot } 1: \text { kanMX6::dot1- } \\
\text { G401V::URA3 }\end{array}$ & This study \\
\hline YP1185 & $\begin{array}{l}\text { BR1919a lys2 ANheI zip1::LYS2 dot } 1:: k a n M X 6:: \operatorname{dot} 1- \\
\text { G401A::URA3 }\end{array}$ & This study \\
\hline W303-1A & $\begin{array}{l}\text { MATa leu2-3,112 trp1-1 ura3-1 ade2-1 his3-11,15 can1-100 } \\
\text { rad5-G535R }\end{array}$ & R. Rothstein \\
\hline W303-1B & $\begin{array}{l}\text { MAT } \alpha \text { leu2-3,112 trp1-1 ura3-1 ade2-1 his3-11,15 can1-100 } \\
\text { rad5-G535R }\end{array}$ & R. Rothstein \\
\hline YAF120 & $\begin{array}{l}\text { W303-1A hhf2-hht2::natMX htal-htb1::hphMX4 hht1- } \\
\text { hhf1::kanMX hta2-htb2::natMX GAL1::YLR454w::TRP1 } \\
<\text { pRS315-HTA1-Flag-HTB1, HHT1-HHF1> }\end{array}$ & {$[46]$} \\
\hline YAF124 & $\begin{array}{l}\text { W303-1A hhf2-hht2::natMX hta1-htb1::hphMX4 hht1- } \\
\text { hhf1::kanMX hta2-htb2::natMX GAL1::YLR454w::TRP1 } \\
<\text { pRS315-HTA1-Flag-HTB1, hht1-K79A-HHF1> }\end{array}$ & [46] \\
\hline YP1332 & YAF120 dot $1:: U R A 3$ & This study \\
\hline YP813 ${ }^{\mathrm{a}}$ & W303-1A RAD5 barl::LEU2 & [51] \\
\hline YP814 & W303-1A RAD5 barl::LEU2 $\operatorname{rad53-3HA::TRP1~}$ & This study \\
\hline YP1215 & W303-1A RAD5 bar1::LEU2 dot1:kanMX6 & This study \\
\hline YP1216 & W303-1A RAD5 bar1::LEU2 dot1:kanMX6 rad53-3HA::TRP1 & This study \\
\hline TH291 & W303-1A RAD5 pol30-K164R & {$[48]$} \\
\hline YP1553 & W303-1B RAD5 barl::URA3 pol30-K164R & This study \\
\hline YP1554 & W303-1A RAD5 barl::URA3 pol30-K164R rad53-3HA::TRP1 & This study \\
\hline YP1217 & W303-1B RAD5 barl::URA3 pol30-K164R dot1::kanMX6 & This study \\
\hline U952-3B & W303-1A RAD5 smll::HIS3 & {$[76]$} \\
\hline YP558 & W303-1A RAD5 sml1::HIS3 dot1::URA3 & This study \\
\hline U960-5C & W303-1A RAD5 sml1-1 rad53::HIS3 & {$[76]$} \\
\hline YP755 & W303-1A RAD5 rad53::HIS3 sml1-1 dot1::kanMX6 & This study \\
\hline
\end{tabular}




\begin{tabular}{|c|c|c|}
\hline YP1471 & W303-1A RAD5 bar1::LEU2 REV1::13myc::HISMX6 & This study \\
\hline YP1458 & $\begin{array}{l}\text { W303-1A RAD5 bar1::LEU2 REV1::13myc::HISMX6 } \\
\text { dot1::kanMX6 }\end{array}$ & This study \\
\hline YP1460 & $\begin{array}{l}\text { W303-1A RAD5 bar1::LEU2 REV1::13myc::HISMX6 rad53- } \\
\text { 3HA::TRP1 }\end{array}$ & This study \\
\hline YP1531 & $\begin{array}{l}\text { W303-1A RAD5 bar1::LEU2 REV1::13myc::HISMX6 pol30- } \\
\text { K164R }\end{array}$ & This study \\
\hline BY4742 & MAT $\alpha$ his $3 \Delta 1$ leu $2 \Delta 0$ ura $3 \Delta 0$ lys $2 \Delta 0$ & {$[77]$} \\
\hline NKI3002 & BY4742 dot1::natMX4 & {$[42]$} \\
\hline NKI3018 & BY4742 dot1 $\Delta:: \operatorname{dot} 1-G 401 V$ & F. van Leeuwen \\
\hline
\end{tabular}

${ }^{\mathrm{a} C}$ Corresponds to strain YLW70 [51]. 
Table 2. Plasmids

\begin{tabular}{lll}
\hline Plasmid & Description & Source/Reference \\
\hline pRS315 & CEN LEU2 & {$[78]$} \\
pRS315-DOT1 & CEN LEU2 DOT1 & {$[42]$} \\
pFvL54 & CEN LEU2 dot1-G401A & {$[42]$} \\
pRS306 & URA3 & {$[78]$} \\
pFF003 & URA3 dot1-G401A & F. van Leeuwen \\
pTW043 & URA3 dot1-G401V & F. van Leeuwen \\
pRS426 & $2 \mu U R A 3$ & {$[79]$} \\
pSS145 & $2 \mu U R A 3$ RAD53 & This study \\
\hline
\end{tabular}


(A)
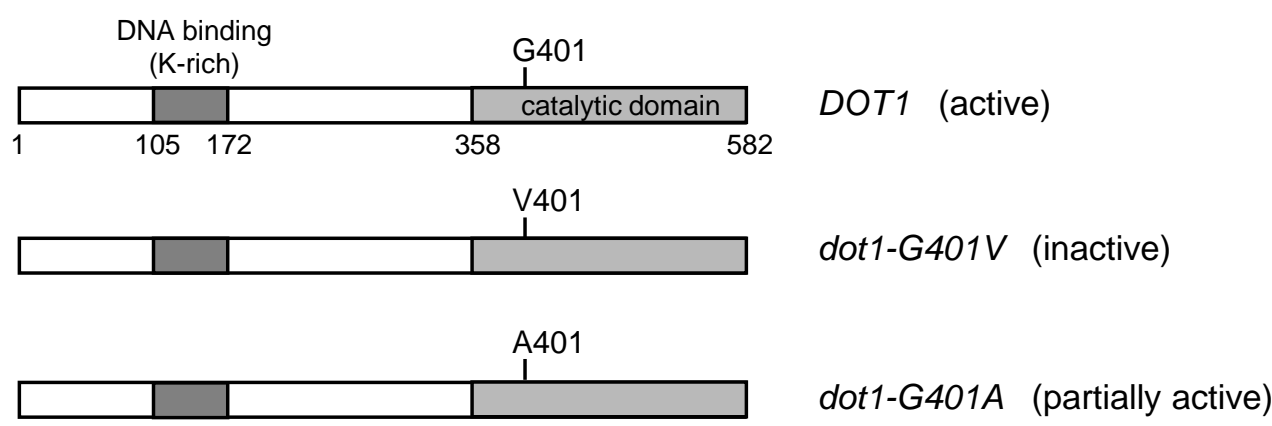

(B)

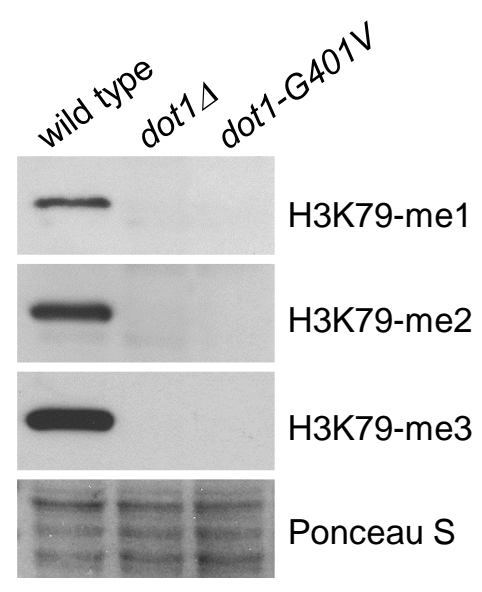

(C)

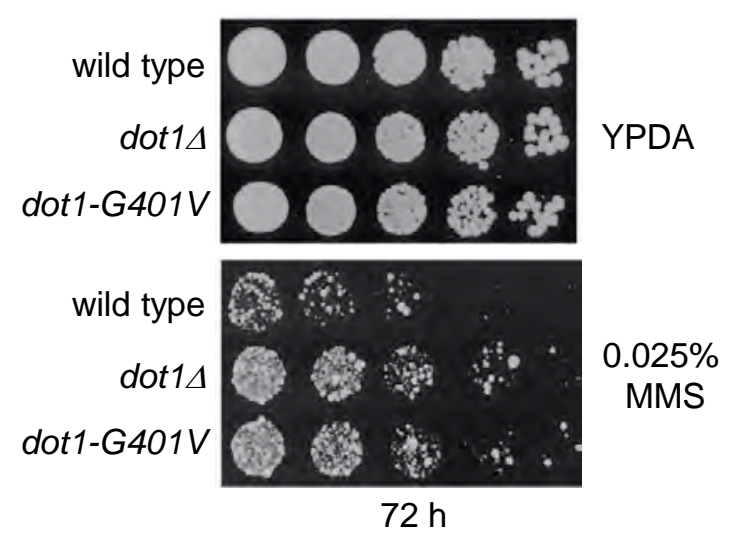

(D)

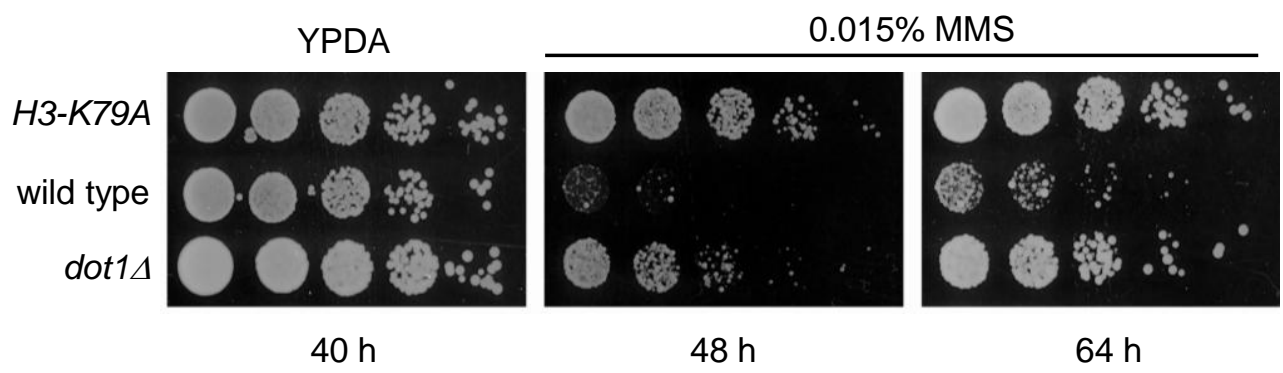

Figure 1 
(A)

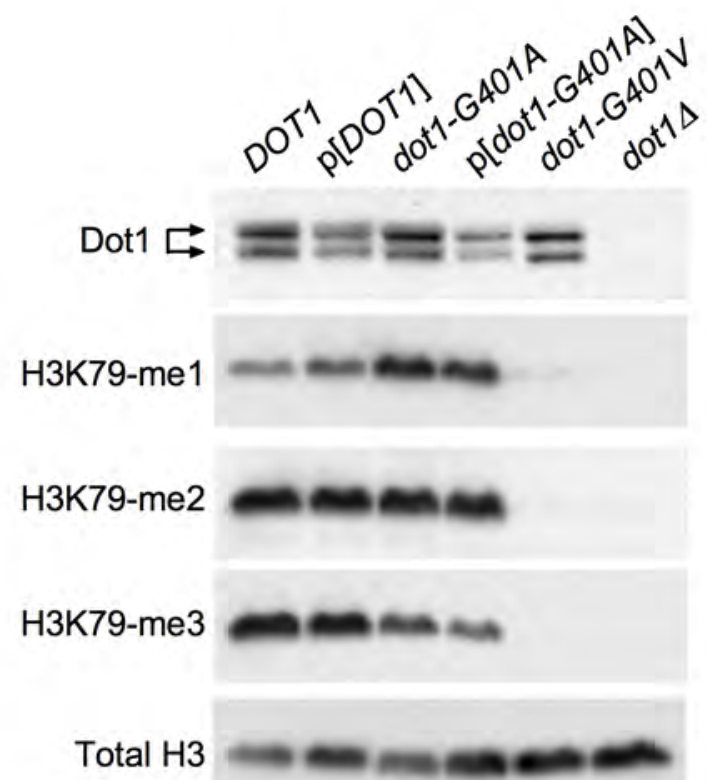

(B)

Dot1 catalytic activity

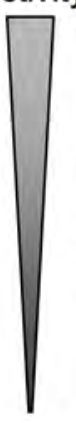

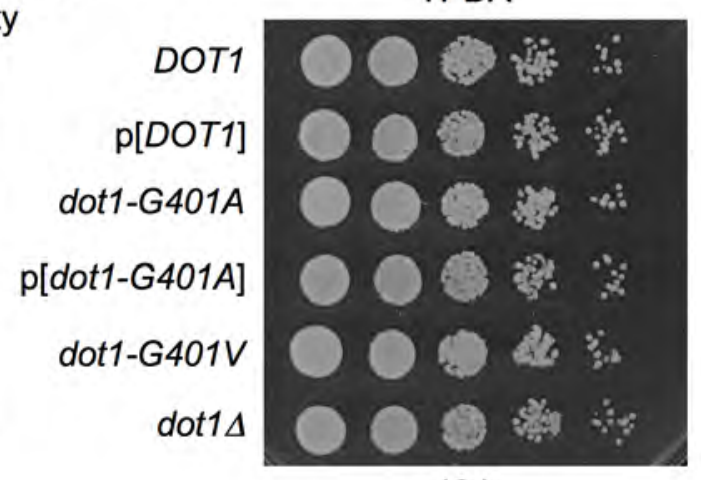

$40 \mathrm{~h}$

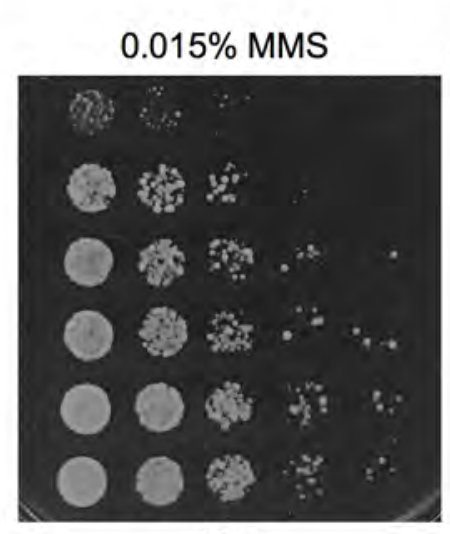

$60 \mathrm{~h}$
MMS resistance

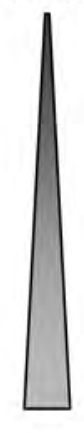

\section{(C)}

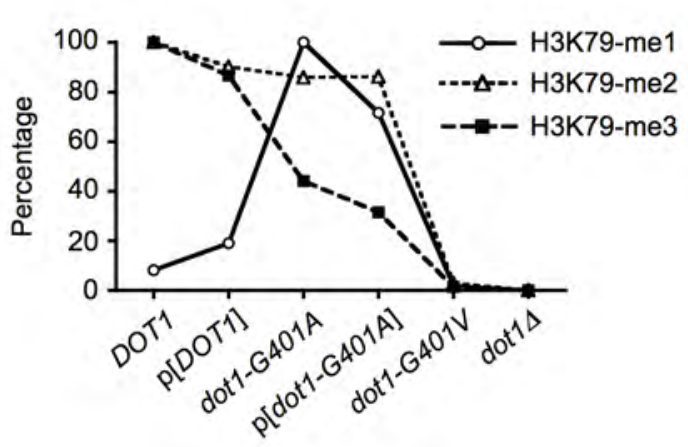

(D)

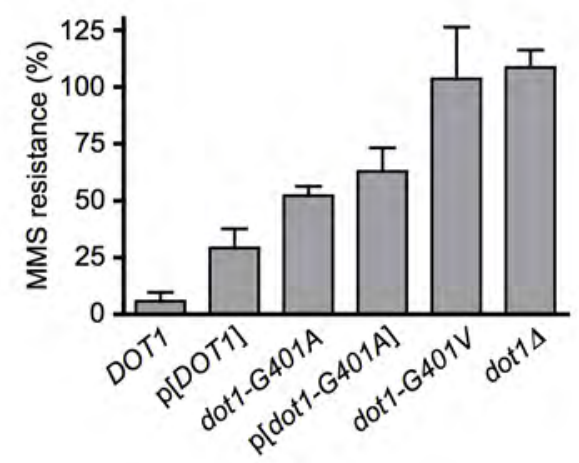


(A)

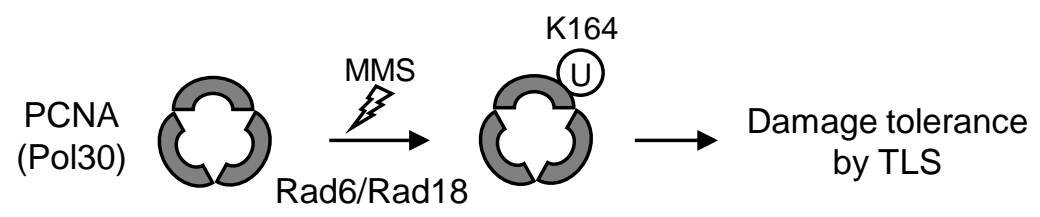

(B)

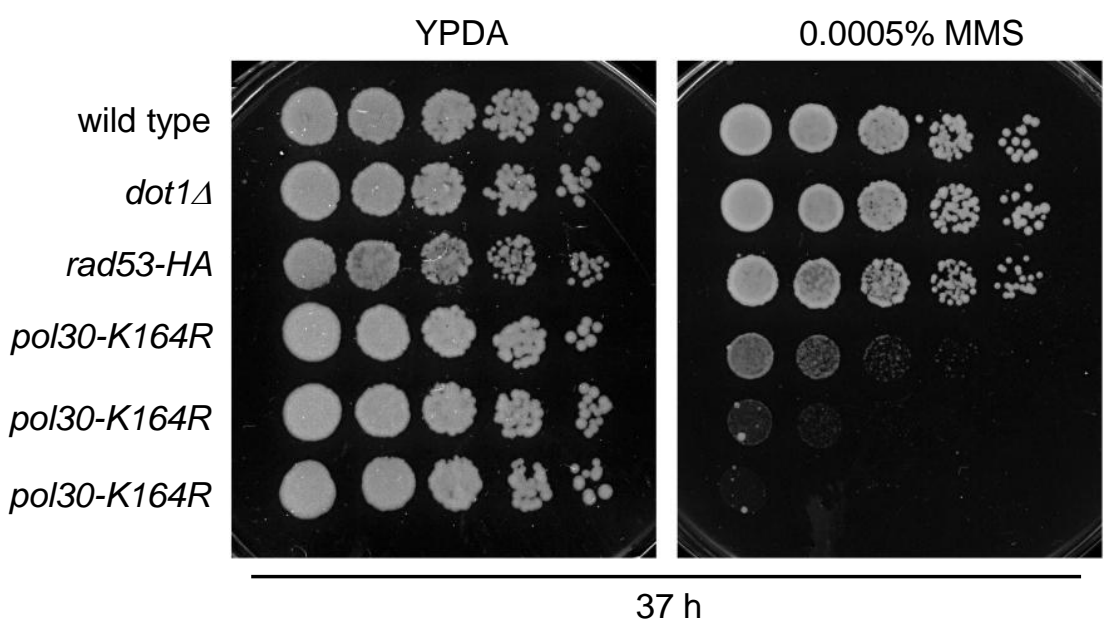

Figure 3 


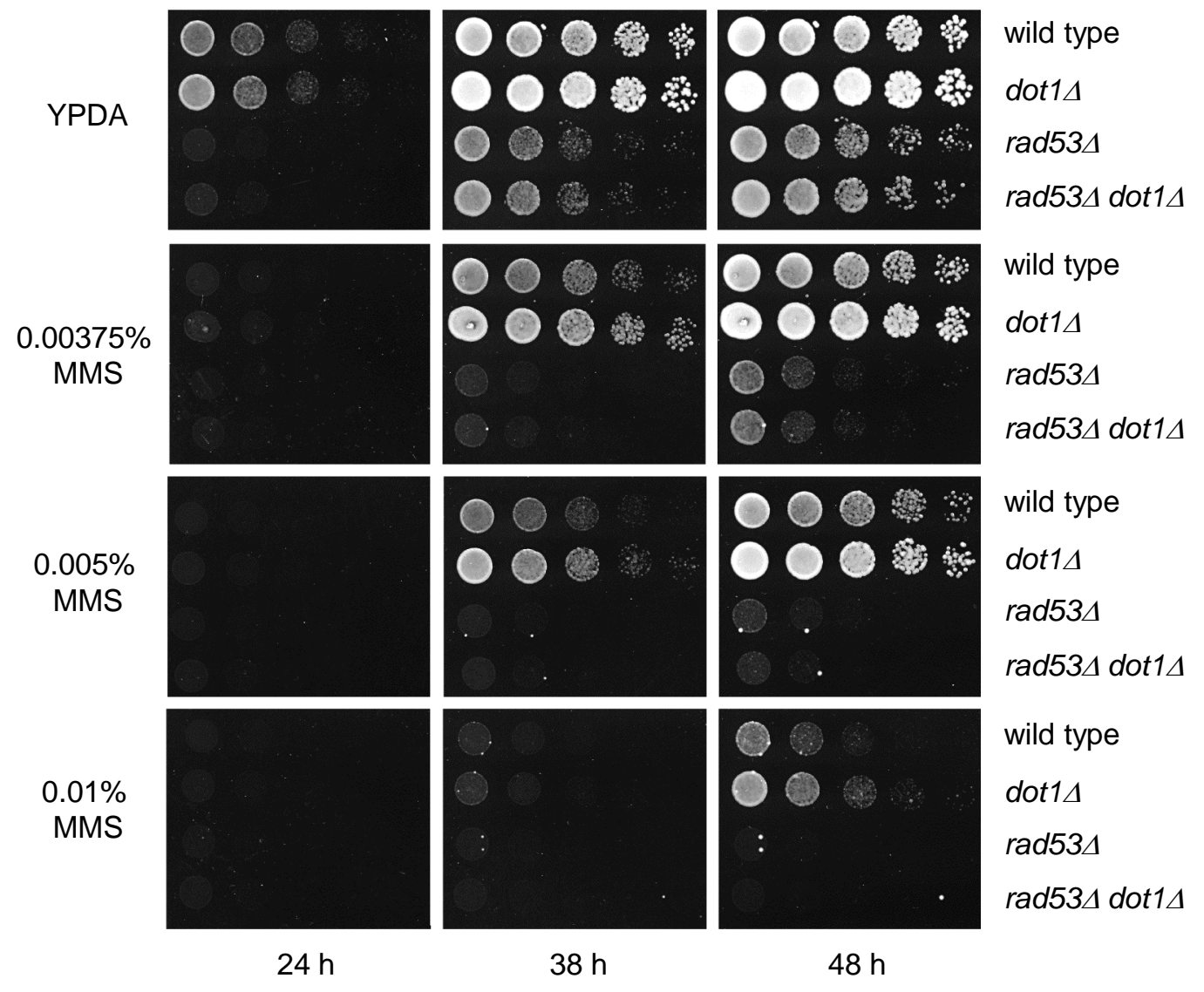

Figure 4 
(A)

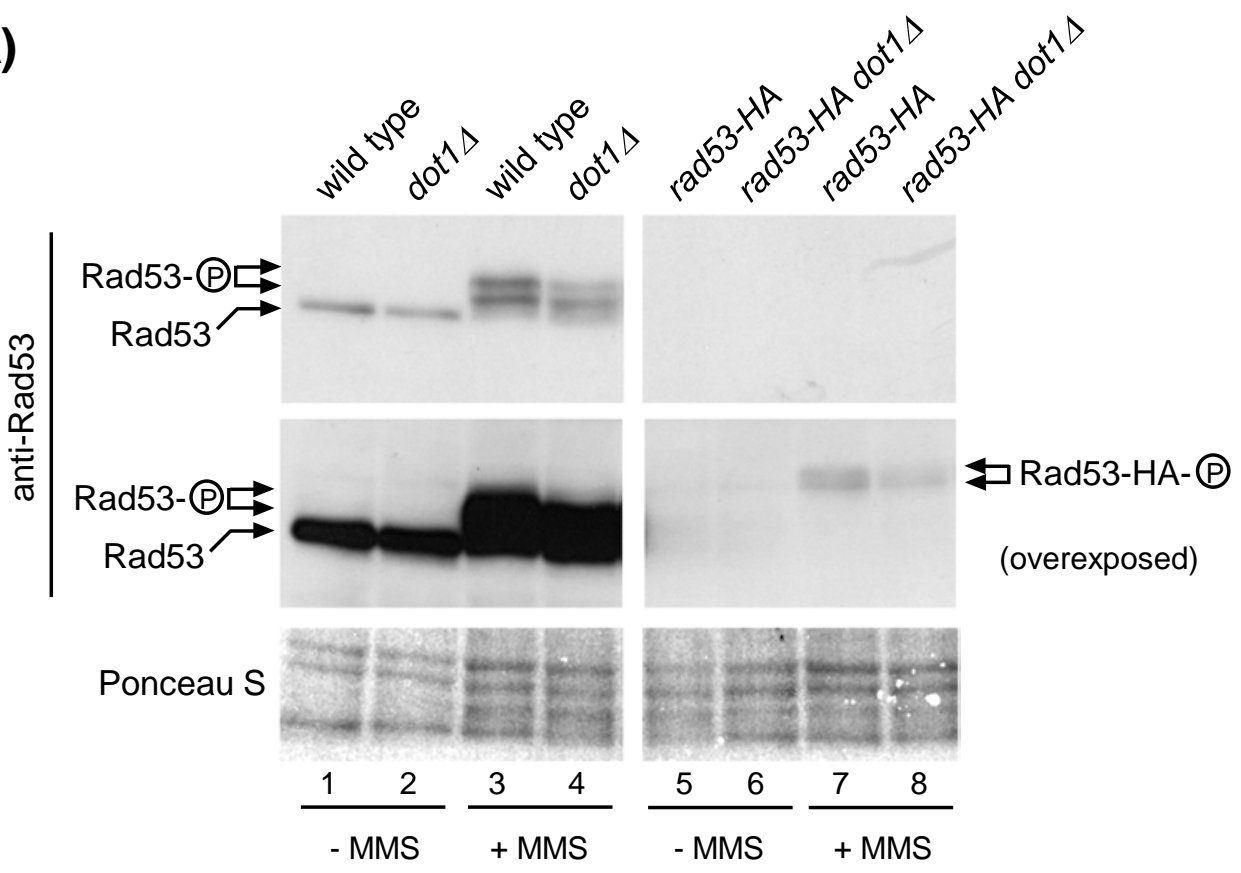

(B)

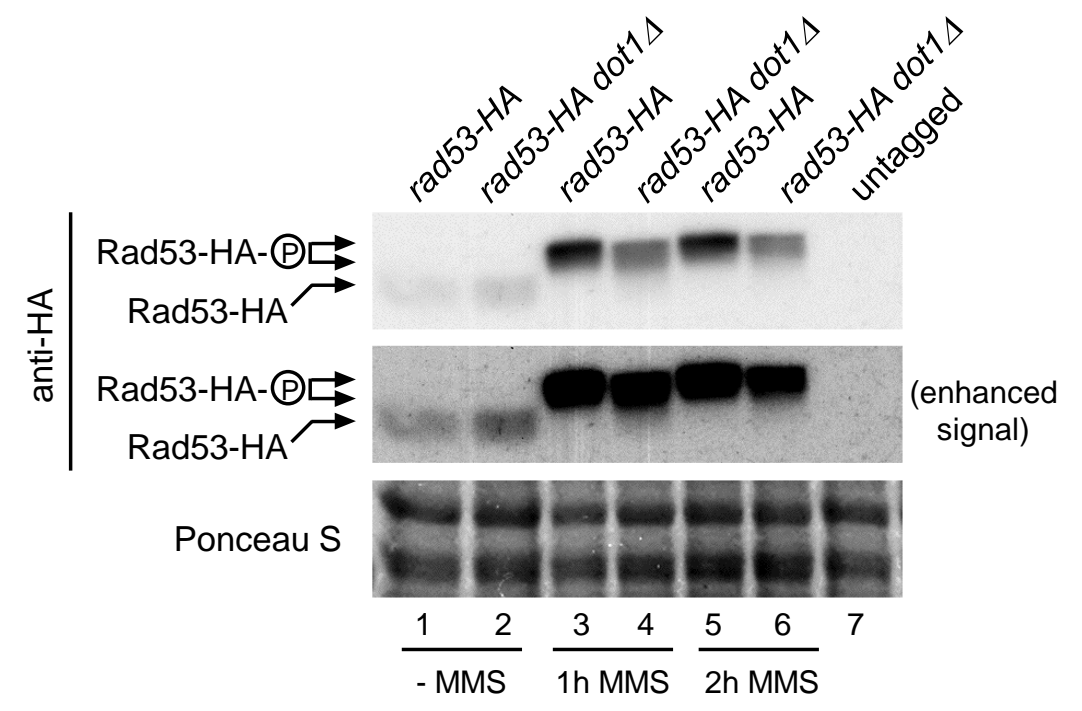

(C)

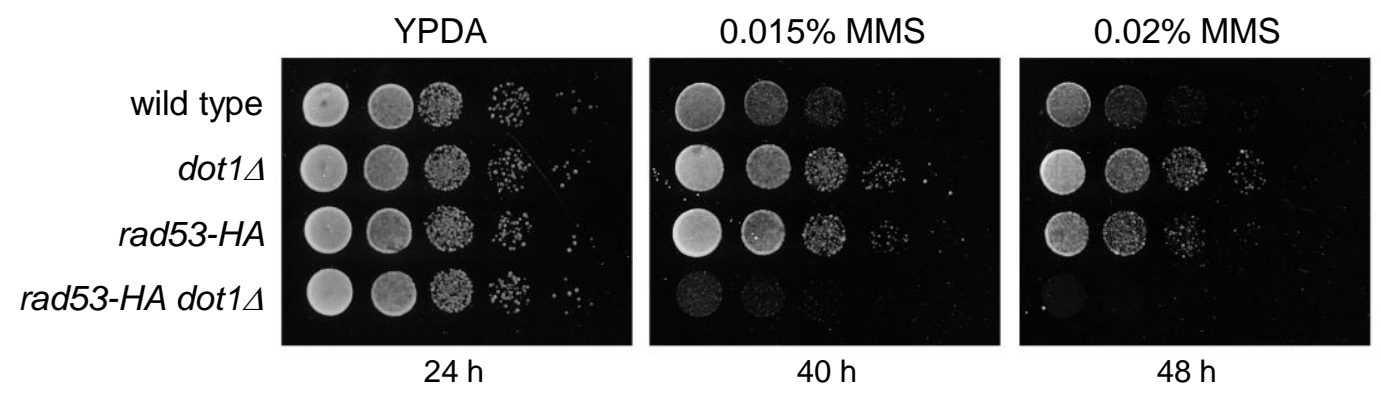

Figure 5 
(A)

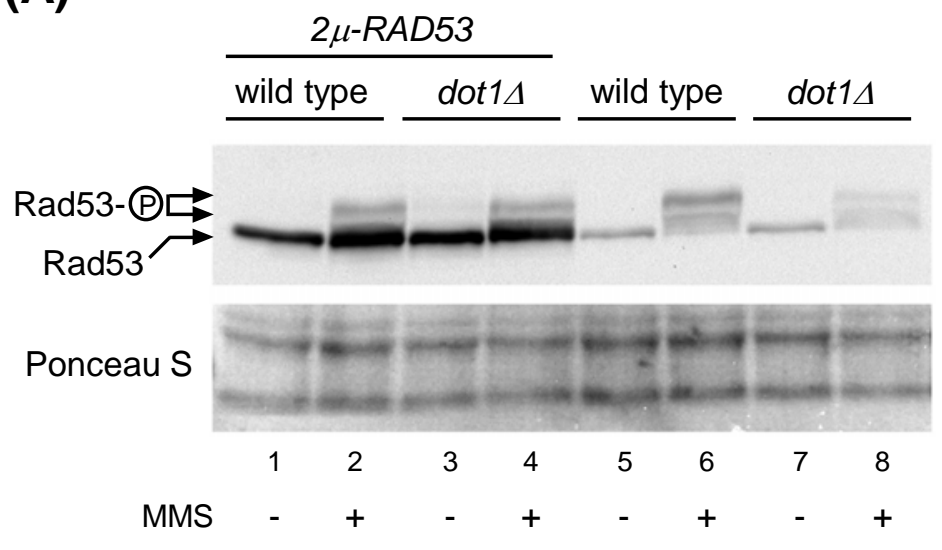

(B)

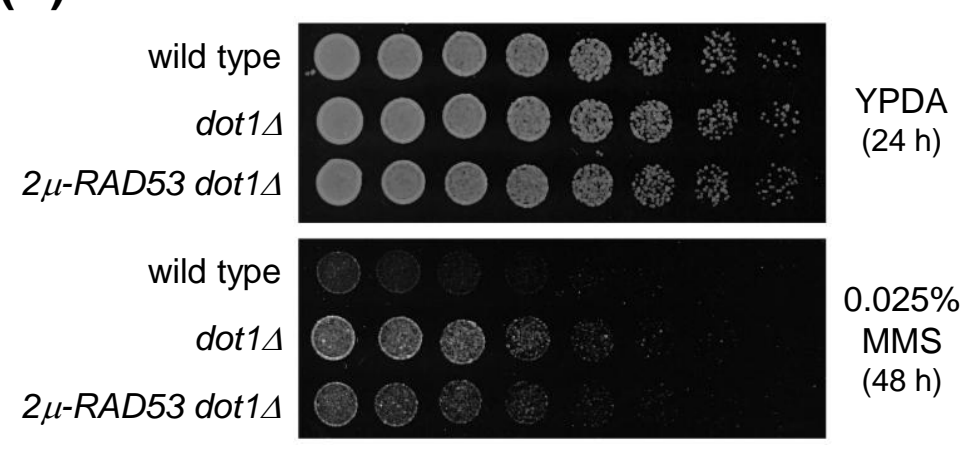

(C)

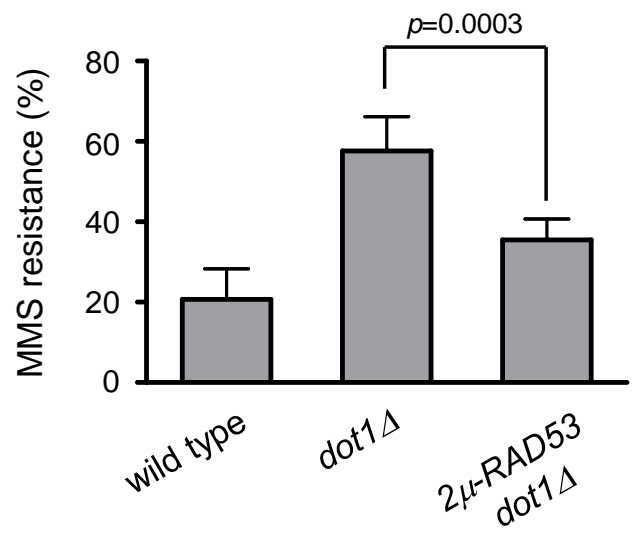

Figure 6 
(A)
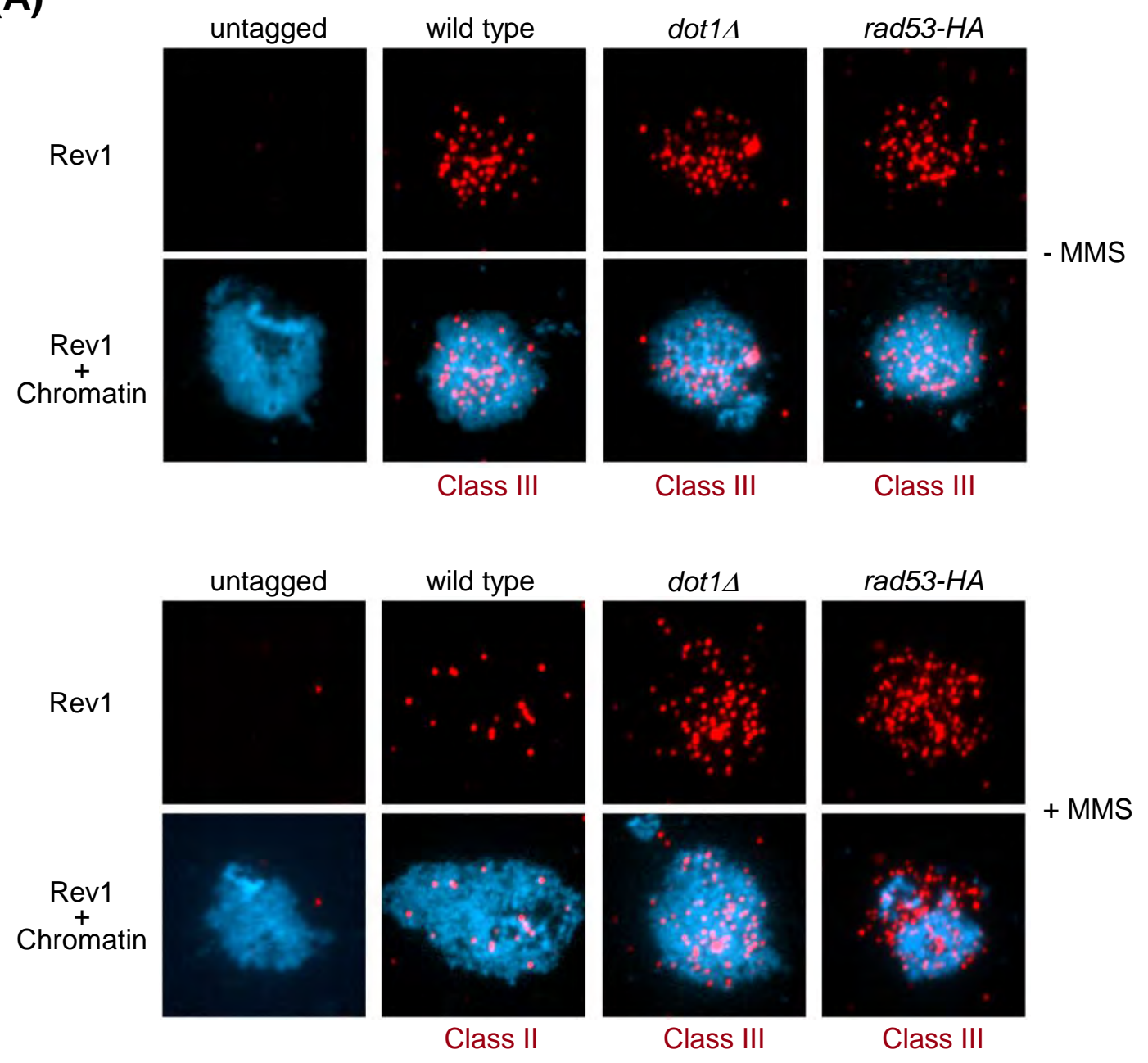

(B)

- MMS

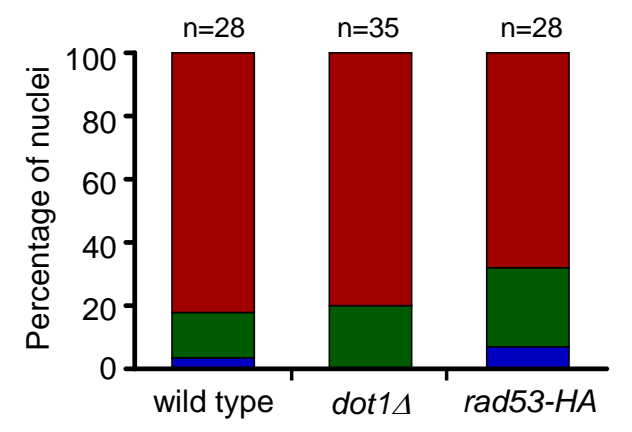

+ MMS

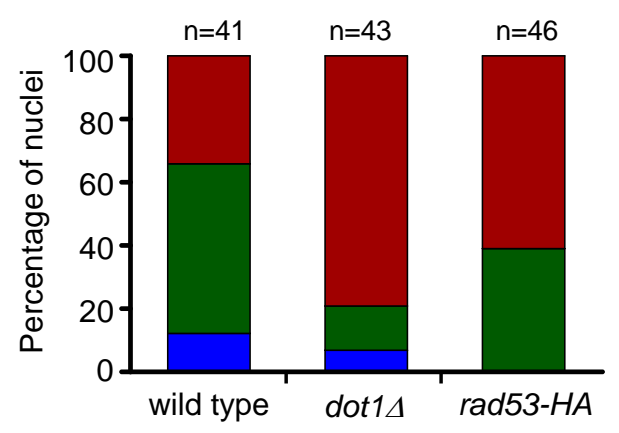

\section{$<10$ foci (Class I)}

11-30 foci (Class II) $>30$ foci (Class III)

Pattern of chromosomal Rev1

Figure 7 
wild type
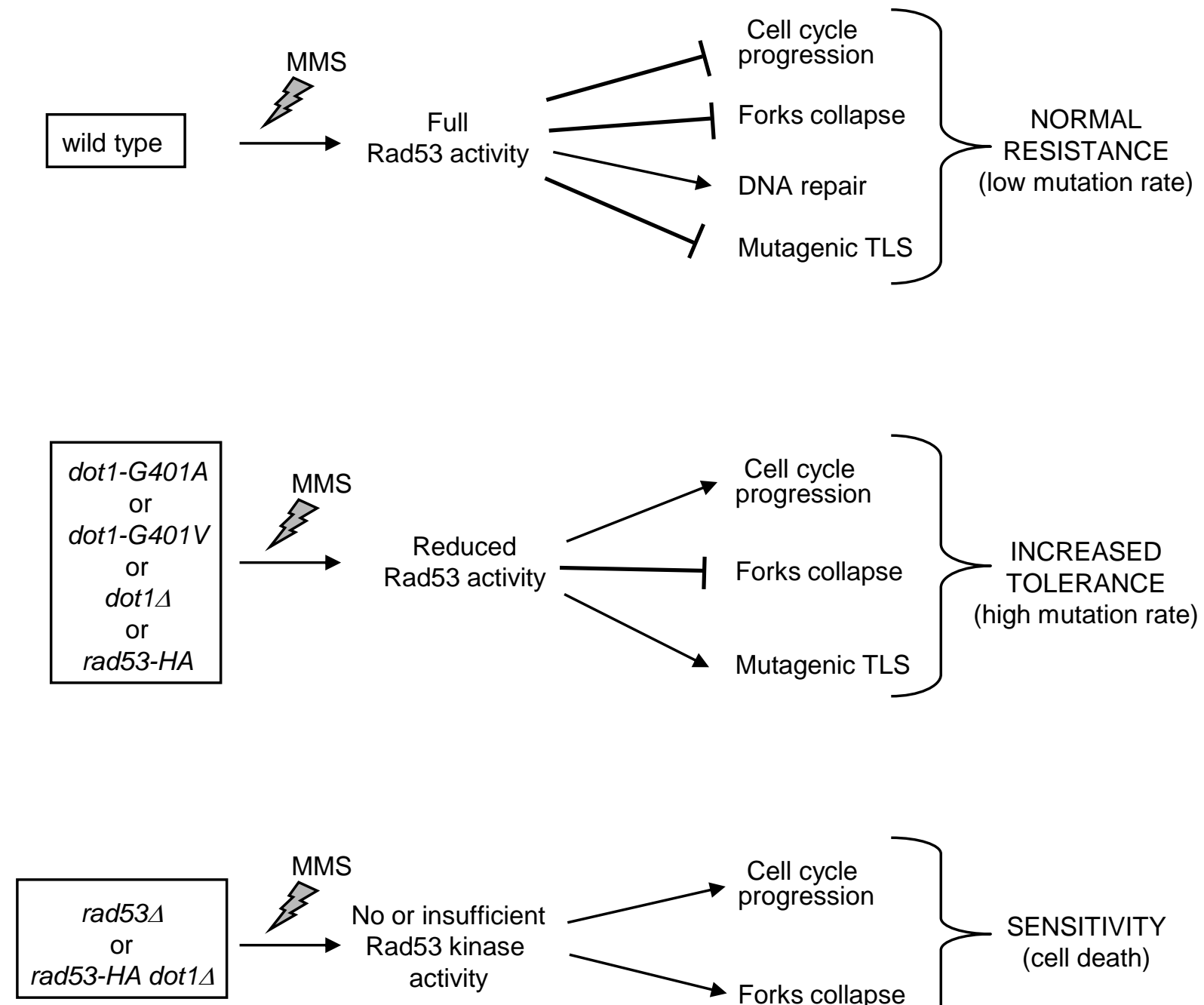

No or insufficient

Rad53 kinase

activity

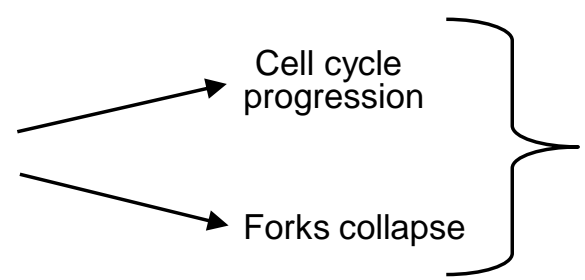

SENSITIVITY

(cell death) 
Supplementary Figure 1
Click here to download S

Supplementary Figure 1
Click here to download Supplementary Material: SUP Fig 1.pdf

\begin{abstract}
Click here to
\end{abstract}
Fig 1.pdf

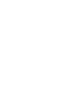

(1)

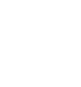

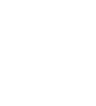
(n) (n)

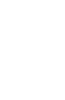
(n)

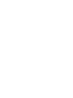
(1)

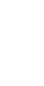

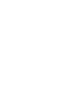

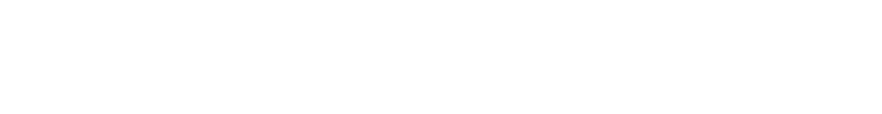

(1) 